Culture and Psychopathology

\title{
Culture and Psychopathology: An attempt at reconsidering the role of social learning
}

Peter Fonagy, Research Department of Clinical, Educational and Health Psychology, University College London, UK; Anna Freud National Centre for Children and Families, London, UK.

Email:p.fonagy@ucl.ac.uk

Chloe Campbell, Research Department of Clinical, Educational and Health Psychology, University College London, UK; Anna Freud National Centre for Children and Families, London, UK.

Email: c.campbell@ucl.ac.uk

Matthew Constantinou, Research Department of Clinical, Educational and Health Psychology, University College London, UK.

Email: matthew.constantinou.13@ucl.ac.uk

Anna Higgitt, Central and North West London NHS Foundation Trust, London, UK

Email: anna.higgitt@nhs.net

Elizabeth Allison, Research Department of Clinical, Educational and Health Psychology, University College London, UK; Anna Freud National Centre for Children and Families, London, UK.

Email: e.allison@ucl.ac.uk

Patrick Luyten, Faculty of Psychology and Educational Sciences, University of Leuven, Leuven, Belgium; Research Department of Clinical, Educational and Health Psychology, University College London, UK.

Email: patrick.luyten@kuleuven.be 
Culture and Psychopathology

Corresponding author: Peter Fonagy, UCL Division of Psychology and Language Sciences, 26 Bedford Way, London WC1H 0AP

p.fonagy@ucl.ac.uk

Funding Statement: PF is in part supported by the NIHR Collaboration for Leadership in Applied Health Research and Care (CLAHRC) North Thames at Barts Health NHS Trust.

Conflict of Interests Statement: PF and PL are involved in the development, training, and dissemination of mentalization-based treatments. While PF derives no personal gain from these activities, he is chief executive of Anna Freud National Centre for Children and Families, a charity that financially benefits from trainings in this modality. Apart from these, the authors are not aware of any affiliations, memberships, funding, or financial holdings that might be perceived as affecting the objectivity of this review.

\footnotetext{
Abstract

This paper proposes a model for developmental psychopathology that is informed by recent research suggestive of a single model of mental health disorder (the $\mathrm{p}$ factor) and seeks to integrate the role of the wider social and cultural environment into our model, which has previously been more narrowly focussed on the role of the immediate care-giving context. Informed by recently emerging thinking on the social and culturally driven nature of human cognitive development, the ways in which humans are primed to learn and communicate culture, and a mentalizing perspective on the highly-intersubjective nature of our capacity for affect regulation and social functioning, we set out a cultural-developmental approach to psychopathology.
} 
Culture and Psychopathology

\section{Culture and Psychopathology:}

\section{An attempt at reconsidering the role of social learning}

\section{Introduction}

When we discuss developmental psychopathology, when we write about attachment, or the dyad, or gene-environment interaction, an elephant in the room is often overlooked. This is the fact that the most powerful predictor of mental illness is socio-economic deprivation (Lund et al., 2018). This is the starting point for the perspective we would like to bring to this paper. We are not aiming to present a naively political or materialist position, in which everything is reduced to socio-economic forces. Rather, we argue that this epidemiological reality needs to be more meaningfully integrated into theoretical models of developmental psychopathology. We will set out here an approach that seeks to locate the social environment around the individual as central to their subjective experience, and their vulnerability to psychological disorder. This is, in part, an evolutionary approach, informed by recently emerging thinking around the social and culturally driven nature of human cognitive development, and the ways in which humans are primed to learn and communicate culture fostered by the capacity for mentalizing which enables the highly-intersubjective nature of our capacity for affect regulation and social functioning. We will set this out in the second half of this paper. But first we would like to outline the case for a new socialcommunicative model of psychopathology in which we suggest that the mechanisms through which culture is maintained and transmitted across generations are overlapping and in places isomorphic with the developmental generation of mental disorder.

\section{Why do we need a new model?}

We will begin with discussion of the difficulties that face our current conceptualisation of psychopathology, and which, we will propose, support thinking about the construction of a unified model of disorder. We will review evidence that points to the appropriateness of a 
Culture and Psychopathology

unified model, following which we will outline our tentative framework for a social communicative model of developmental psychopathology. We suggest that the fragmentation of mental disorder into hundreds of diagnostic groupings driven by the pragmatism of practice and the application of prescriptive models of treatments has impeded the understanding of the way global influences such as culture effect the development of mental disorder. The RDoC movement demonstrated that the understanding of disease mechanisms requires abandoning phenomenologically rooted categories of disorder (Insel et al., 2010). We will review evidence that points to the appropriateness of a single, unified conceptualisation of psychopathology which offers a frame for understanding how culture interfaces with the emergence of mental disorder.

Clinical problems: comorbidity and severity

Perhaps the most acutely felt source of dissatisfaction with diagnostic taxonomies is the high degree of comorbidity which affects the majority of individuals who meet criteria for any one diagnosis (Kessler, Chiu, Demler, Merikangas, \& Walters, 2005). Comorbidity transcends diagnoses, and overlap is observed between most symptoms known to be associated with mental disorder (e.g. Budde et al., 2018). Comorbidity is ubiquitous among all common mental disorders (Caspi et al., 2014; Copeland, Shanahan, Erkanli, Costello, \& Angold, 2013). From the perspective of developmental psychopathology, comorbidity may be considered largely artefactual due to nosology splitting disease entities into sub-categories that likely lack validity (Beauchaine \& Cicchetti, 2016; Forbes, Tackett, Markon, \& Krueger, 2016). If disorders were reconceptualized as indicators of latent transdiagnostic spectra, comorbidity would no longer be a problem. Indeed, if disorders share phenotypic and genotypic variance, comorbidity seems an inappropriate and unhelpful term that could be readily replaced by the phrase "frequent co-occurrence" (Goldberg, 2015). The term 
Culture and Psychopathology

comorbidity should be reserved for etiologically distinct disorders such as bipolar disorder and hiatus hernia, as was originally intended (Feinstein, 1970).

A second, equally problematic area in relation to the diagnosis of mental disorder is the concept of severity. A paper by Zimmerman, Morgan, and Stanton (2018) demonstrates that the generally used concept of severity has no reliable agreed referent, either across diagnostic categories or, at closer scrutiny, even within disorders. It is used variously to refer to: number of symptoms, the intensity of symptoms, the frequency or persistence of symptoms, the impact of symptoms on quality of life or general adaptation, the likelihood of permanent disability or death etc. Although DSM-5, in a number of instances, offers specific criteria for quantification or qualification, these are in most instances not validated against external criteria or in universal use (American Psychiatric Association, 2013). Zimmerman et al. (2018) systematically examined the way severity has been conceptualised and researched in relation to depression and personality disorders. In both cases, treatment recommendations are made with reference to treatment severity (National Institute for Health and Care Excellence, 2017; National Institute for Health and Clinical Excellence, 2012). For example, two meta-analyses used a cut-off of 20 or more on the 17-item Hamilton Rating Scale for Depression (DeRubeis, Gelfand, Tang, \& Simons, 1999; Gibbons, Hur, Brown, Davis, \& Mann, 2012) using Elkin et al.'s (1995) landmark study as justification. A difficulty with this is that Elkin et al. (1995) cited no evidence for using that particular cut-off score. Other studies cite different cut-offs for the same instrument (Dunner, Lipschitz, Pitts, \& Davies, 2005; Kirsch et al., 2008; Zimmerman, Martinez, Young, Chelminski, \& Dalrymple, 2013) but each also uses clinician's global judgement of severity (CGI). Of course, a further issue is that we do not know how clinicians weight various symptoms as they assign CGI ratings alongside a HAM-D assessment. Using different scales, we find quite different metrics for the classification of severity (Zimmerman et al., 2012). The picture in relation to the severity 
Culture and Psychopathology

of personality disorder is even more confusing. Does it refer to co-occurring disorders (Links \& Eynan, 2013) or other PD diagnoses (Bateman \& Fonagy, 2013) or more severe symptoms such as self-injury (Zanarini et al., 2002) or indication of social functioning (Yang, Coid, \& Tyrer, 2010)? These and over 200 references in the review of Zimmerman et al. (2018) point to a profound current difficulty in the use of the severity concept as nested within diagnoses. But apart from severity, how do we judge the general seriousness of psychopathology? Is cooccurrence/comorbidity equivalent to severity? Is persistence/treatment resistance an overlapping construct? One potential answer may be in the psychometric construct of the $p$ factor.

\section{Psychometric evidence}

A compelling tranche of evidence for a singular model for psychopathology derives from recent work in factor analysis. A method of capturing underlying covariation amongst a number of variables is the so-called bi-factor model, which assumes that all variables have common variance explained by a single factor independent of covariance accounted for by clusters of such variables (spectral level factors, e.g., internalizing and externalizing) (Markon, 2019). The $\mathrm{p}$ factor is thus a statistical summary of the variance common to symptoms, across diagnoses and spectral clusterings (Caspi et al., 2014). It was so labelled by Caspi and colleagues to assist in making the conceptual leap from Spearman's intelligence manifold (the $\mathrm{g}$ factor). Both the general factor (e.g., $\mathrm{p}$ factor) and specific factors (e.g., internalizing, externalizing) contribute to the ways in which symptoms or disorders positively co-occur with each other, but the majority of what we measure using interviews or questionnaires is underpinned by the general factor (Constantinou \& Fonagy, 2019). The bifactor model consistently outperforms other models in describing the covariation in psychopathology data across children (Lahey et al., 2015; Moore et al., 2020; Olino et al., 2018; Sallis et al., 2019), adolescents (Castellanos-Ryan et al., 2016; Laceulle, Vollebergh, \& 
Culture and Psychopathology

Ormel, 2015; Patalay et al., 2015; Snyder, Young, \& Hankin, 2017b) and adults (Caspi et al., 2014; Gluschkoff, Jokela, \& Rosenström, 2019; Lahey et al., 2012; Lahey et al., 2018). Some of the above studies indicate that the $\mathrm{p}$ factor best accounts for covariation among disorderlevel indicators, while others demonstrate the bifactor model's superiority using symptomlevel indicators, though the $\mathrm{p}$ factor may not represent all covariation between specific spectral factors and common variance remains for specific dimensions to be correlated (Carragher et al., 2016; Caspi et al., 2014). The p factor appears to capture an underlying propensity for any kind of psychopathology (Caspi \& Moffitt, 2018) or an overall index of seriousness or impairment (Smith, Atkinson, Davis, Riley, \& Oltmanns, 2020), which can be represented as a global statistic that is open to external validation.

A number of methodological issues need to be resolved before the concept of a general psychopathology factor could be widely adopted by developmental researchers and clinicians. First, symptoms are shared across disorders, both within and between spectral level factors; this could generate the appearance but not the reality of a general psychopathology factor. For example, both adolescent depression and antisocial personality disorder are characterised by irritability. However, when these overlapping symptoms are removed, the general model remains unchanged (Lahey et al., 2018). Some have suggested that common method variance, shared biases, positive or negative halo effects etc. could account for a general factor. Modern psychometrics, however, recognises that traditional "nuisance" variables (such as confirmatory bias) are better seen as part of what one wishes to measure rather than something to exclude (Podsakoff, MacKenzie, Lee, \& Podsakoff, 2003). In a comprehensive, multi-trait multi-method analysis, positive covariation among a range of disorders was shown to exist across ratings from different informants (Lahey, Krueger, Rathouz, Waldman, \& Zald, 2017), meaning that it is not simply biased responding from a given informant that drives the positive manifold. It is more difficult to rebut criticisms that 
Culture and Psychopathology

the bi-factor model may be repeatedly favoured over competing models such as the traditional correlated factor model because it is better at accommodating noise in the data (i.e. the problem of 'overfitting' (Greene et al., 2019; Murray \& Johnson, 2013; Reise, Kim, Mansolf, \& Widaman, 2016) or is statistically more complex than its counterparts (Bonifay \& Cai, 2017), meaning fit indices favour the bifactor model for statistical rather than substantive reasons. Others have argued that the bi-factor model simply redistributes the covariance among observed indicators rather than providing a new model of sorts (Vine et al., 2020; Watts, Poore, \& Waldman, 2019). Some have even called into question whether a general factor is necessary or sufficient to explain the positive manifold among symptom items (van Bork, Epskamp, Rhemtulla, Borsboom, \& van der Maas, 2017). In order for the bi-factor model to be meaningfully applied to research and practice, there have been calls to move beyond model fit indices and evaluate the general and specific dimensions against external criteria to test theoretical predictions (Bornovalova, Choate, Fatimah, Petersen, \& Wiernik, 2020; Sellbom \& Tellegen, 2019).

If the $\mathrm{p}$ factor signals a general predisposition to mental disorder which we wish to establish here, then it should be associated with independent measures of risk factors for psychopathology. Indeed, higher $p$ factor scores are associated with early adverse experiences and a family history of psychopathology (Caspi et al., 2014; Deutz et al., 2020; Hyland et al., 2020; Lahey et al., 2012; Martel et al., 2017; Schaefer et al., 2018). Of particular relevance to the current paper, the $\mathrm{p}$ factor is also associated with markers of socio-economic disadvantage, whether they are assessed cross-sectionally (D. W. Belsky, Caspi, A., Arseneault, L., Corcoran, D. L., Domingue, B. W., Harris, K. M., . . Odgers, C. L. , 2019; Lahey et al., 2012; Patalay et al., 2015), prospectively (Blanco et al., 2019; Caspi et al., 2014; Schäfer et al., 2020), or longitudinally (Snyder, Young, \& Hankin, 2017a; Wade, Fox, Zeanah, \& Nelson, 2018). Furthermore, heightened p factor scores in adolescence are 
Culture and Psychopathology

associated with experiences of racial discrimination (Liu, Mustanski, Dick, Bolland, \& Kertes, 2017), and higher p scores in adulthood are independently predicted by experiences of childhood and adolescent victimization, after accounting for genetic liabilities and preexisting symptomatology (Schaefer et al., 2018). This growing body of research demonstrates that experiences of social exclusion and disadvantage in the family, peer and neighborhood environments contribute to one's general susceptibility to mental ill-health calling for a comprehensive developmental psychopathology account of putative mechanisms.

\section{Genetic evidence}

Genetic evidence from both behaviour genetics and molecular biology is also consistent with the general psychopathology argument. Behaviour genetic studies on families and twins tend to show that genetic risk is not specific to particular disorders. Rather it is largely a transdiagnostic vulnerability. However, the literature also offers evidence for genetic associations at some specific spectral level factors. Several studies report factor analyses of genetic correlations based on twin samples. In these studies, a variable number of syndromal categories are identified and the configuration of spectral factors differs, but evidence consistently points to almost all the genetic covariance being explained by a general genetic factor (Lahey, Van Hulle, Singh, Waldman, \& Rathouz, 2011; Pettersson, Larsson, \& Lichtenstein, 2016; Selzam, Coleman, Caspi, Moffitt, \& Plomin, 2018; Waldman, Poore, Luningham, \& Yang, 2020). The notion of a general vulnerability to psychopathology, regardless of diagnosis, is supported by family studies that show a general rising of risk of mental disorder with increased relatedness given a diagnosis of severe mental disorder in a proband (Song et al., 2015). There is little evidence for diagnosis-specific genetic influence (Wolf et al., 2010). In terms of specific spectral levels, externalising (e.g. aggression, conduct problems) has a high genetic influence (Waldman, Poore, van Hulle, Rathouz, \& Lahey, 
Culture and Psychopathology

2016). In contrast, non-shared environmental influences may be specific to diagnoses (Waldman et al., 2016).

Molecular genetic studies confirm that phenotypic similarity can be accounted for by concordance at the molecular level (Cross-Disorder Group of the Psychiatric Genomics Consortium, 2013; Lee et al., 2013). A genome-wide association study of 25 brain disorders and 17 mental disorders from over 1 million participants reveals that mental disorders shared common variance risks (Brainstorm Consortium et al., 2018). This was less evident for brain disorders, normally considered neurological, which appear more distinct from each other. The findings confirm the importance of common genetic variation as a risk factor for mental disorders. Genetic evidence suggests that heritability will be increased at the higher order within a hierarchical structure and lowest at first order dimensions at the levels of symptoms (Budde et al., 2018). Single nucleotide polymorphism studies confirm that roughly $50 \%$ of the variance in heritability estimates is explained by a general psychopathology factor, with lower estimates associated with specific internalising or externalising factors (Harden et al., 2019; Neumann et al., 2016; Rosenström et al., 2019). This is consistent with the assumption that the same gene may have a role to play in the range of disorders (Lee et al., 2013; Smoller, 2013). This certainly seems to be evident from studying mental health risks associated with a single gene such as $22 \mathrm{q} 11.2$, whose deletion appears to create mental health risks well captured by a bi-factor model (Niarchou et al., 2017).

\section{Neuroscientific evidence}

Neurobiological causal models that link to the assumption of a singular model of mental disorder most commonly invoke dysfunction of the prefrontal cortex (Macdonald, Goines, Novacek, \& Walker, 2016, p. 1148). There is evidence from meta-analytic studies of reduced grey matter volume in the PFC and limbic regions of individuals with mental disorder (Wise et al., 2016). In a bi-factor analysis of over 2,500 11-year-olds, the p factor predicted reduced 
Culture and Psychopathology

grey matter volume in the dorsal, orbito-frontal and ventro-lateral regions in the PFC (Snyder, Hankin, Sandman, Head, \& Davis, 2017). In a sample of over 1000 16-year-olds, Kaczkurkin et al. (2018) found that the p factor predicted blood perfusion abnormalities in regions of the anterior cingulate cortex, a frontal region involved in effortful control. These findings are of particular developmental interest as these were relatively young samples and therefore an explanation couched in terms of the shared accumulated consequences of mental disorders or their treatment is less plausible.

Other studies have linked the $\mathrm{p}$ factor to disturbed connectivity in fronto-temporal (Alnæs et al., 2017) and fronto-parietal networks (Elliott, Romer, Knodt, \& Hariri, 2018), delayed maturation of the default mode network (which includes medial-prefrontal, cingulate, and parietal regions), and structural alterations in fronto-thalamo-cerebellar networks (Moberget et al., 2019; Romer et al., 2018; Romer et al., 2019). Any neurobehavioral mechanism(s) mediating the association between neural function and psychopathology would need to be sufficiently broad enough to account for the involvement of multiple networks involved in coordinating and controlling thought and behaviour (Romer et al., 2020).

One candidate is executive function, which encompasses the higher order processes for directing and regulating one's thoughts, emotions and behaviours according to one's goals and context (Diamond, 2013). Neuroimaging studies of executive functioning point to the same core problem across many disorders. A meta-analysis of almost 300 studies of executive functioning in 5,500 patients and 5,700 controls reported common impairments associated with the neuro-circuitry during cognitive control paradigms across diagnostic groups (McTeague et al., 2017). This entailed the multiple demand network (Crittenden, Mitchell, \& Duncan, 2016): the left prefrontal cortex, the interior insula, the right ventrolateral prefrontal cortex, the right intra-parietal sulcus and the mid cingulate presupplementary motor area. To note, this comprehensive analysis also revealed anomalous 
Culture and Psychopathology

activation associated with executive function in the anterior dorsal and anterior cingulate cluster, including the insula which has been in previous large scale meta-analyses shown to be prone to grey matter loss across mental disorders irrespective of diagnoses (Goodkind et al., 2015). In a study involving 1,600 participants (Shanmugan et al., 2016) who were evaluated using a structured clinical interview and who performed a working memory task with fMRI, bi-factor analysis of the 112-item interview revealed a general factor and four spectral level factors. Specific spectral level factors (externalizing, internalizing and thought disorders) did not relate to $\mathrm{EF}$, but the $\mathrm{p}$ factor predicted both performance and executive system activation in the frontal pole, the anterior cingulate cortex, anterior insula, thalamus and precuneus. There were also significant regional diminutions associated with the specific spectral level factors (e.g. behavioural symptoms were associated with hypo-activation of the fronto-parietal cortex and cerebellum; psychosis-spectrum symptoms with hypo-activation of the left dorsolateral prefrontal cortex). The results confirm that anomalous brain function areas concerned with the executive system are associated with trans-diagnostic psychopathology but once these are identified, specific associations with particular groupings of disorders are likely to emerge.

In line with this argument, executive function deficits have been demonstrated for almost all diagnoses, including the most serious psychotic disorders (Sellers, Wells, \& Morrison, 2018), as well as pre-psychotic conditions (Dickson et al., 2018) and bipolar disorder (Lima, Peckham, \& Johnson, 2018). EF deficit has been associated with autism (Demetriou et al., 2018), unipolar depression (Knight, Air, \& Baune, 2018) including suicidal tendencies (Ho, Hsu, Lu, Gossop, \& Chen, 2018), ADHD (Kofler et al., 2018), conduct problems (Delfin, Andine, Hofvander, Billstedt, \& Wallinius, 2018), anxiety (Unterrainer et al., 2018), binge eating (Kittel, Schmidt, \& Hilbert, 2017), antisocial personality disorder (Dolan, 2012), and borderline personality disorder (Ernst et al., 2018). Studies that test more 
Culture and Psychopathology

than one clinical group commonly find EF deficits in all (Nigg et al., 2017; Sedgwick et al., 2017) and executive dysfunction correlates positively with both internalising and externalising dimensional scores (Snyder, Miyake, \& Hankin, 2015).

How can we understand these consistent associations? The link may be to some general underlying dysfunction that all mental disorders share, such as the inability to control attention and direct it to goal-relevant information (Beauchaine \& Thayer, 2015; Cirino et al., 2018; Friedman \& Miyake, 2017). It is possible that the shared dysfunction is restricted to emotional challenges such as the capacity to shift attention away from threatening stimuli (Drabick, Ollendick, \& Bubier, 2010) or the control of behavioural impulses (McGrath et al., 2016). There is certainly a growing body of evidence that links EF deficits with the $p$ factor (Bloemen et al., 2018; Caspi et al., 2014; Castellanos-Ryan et al., 2016; Harden et al., 2019; Hatoum, Rhee, Corley, Hewitt, \& Friedman, 2018; Martel et al., 2017; Shields, Reardon, Brandes, \& Tackett, 2019; Snyder, Friedman, \& Hankin, 2019; White et al., 2017), and preliminary evidence showing that poorer EF mediates the link between childhood neglect (as indexed by institutionalization) and later $\mathrm{p}$ factor scores in adolescence (Wade, Fox, Zeanah, $\&$ Nelson, 2019). There is a limitation to this literature, however, in that demonstrations of EF deficit in different clinical groups often use different measures of EF pertaining to different EF domains (Hatoum et al., 2018).

Taken together, structural neuro-imaging and behavioural evidence points to a specific, plausible common cause for mental disorder as a category. The implication here is not so much whether executive function anomalies do or do not offer an adequate account of general psychopathology. The point of interest is that the variance shared by symptoms and syndromes can be meaningfully predicted by specific behavioural observations which in turn connect with likely neuro-developmental anomalies. EF deficits may not be the cause of psychopathology but may be part of a general model of mental disorder that we are seeking to 
Culture and Psychopathology

identify - such deficits may generate vulnerability, creating the potential for mental disorder in response to specific experiences/stressors.

In previous publications we have advanced the view that developmental limitations to mentalising may be a shared by a wide range of mental disorders (Fonagy \& Luyten, 2009; Luyten, Campbell, Allison, \& Fonagy, 2020a). Here we would like to consider the idea that in order to experience a sense of purposeful connection to their broader social community, the individual needs to feel that $\mathrm{s} / \mathrm{he}$ is recognised as an agent and that $\mathrm{s} / \mathrm{he}$ is being mentalized by their social system (Fonagy et al., 2009; Twemlow, Fonagy, \& Sacco, 2013). Mentalizing theory has always maintained that when our immediate social context, conceptualised dyadically, does not provide this kind of experience, we are vulnerable to the development of psychopathology. (Fonagy \& Luyten, 2009; Luyten et al., 2020a). Here we will explore the proposition that psychopathology and socio-economic alienation and inequality are linked in the disadvantaged individual's experience of a broader social context that fails to communicate the subjective richness of the individual minds of those with less economic value or social capital reflecting highly unequal social systems.

\section{The development of culture and the role of culture in human development}

In this section we will set out the context to our thinking about the evolution of social cognitive and culture-building capacities that has inspired our social-communicative approach to developmental psychopathology. The notion that the roots of psychopathology and culture are shared has a distinguished history, not least in the ideas advanced by Sigmund Freud in Civilisation and its Discontents (Freud, 1930). Bronfenbrenner's ecological approach where culture is often considered as part of the exo- and macrosystem which has distal, contextual, or situational influence, has been particularly influential (Bronfenbrenner, 1979). More recently, Causadias (2013) pointed out that even when culture is considered in developmental contexts it is contemplated in terms of environmental influences on 
Culture and Psychopathology

development, or in non-developmental terms, as an attribute of individuals in particular populations. In line with the aims of this paper, Causadias (2013) proposes to conceptualize culture in developmental terms and examine these at the level of both the individual and social group. Causidias maps out four scientific concerns (Causadias, 2013; Causadias \& Cicchetti, 2018): (1) to explore at the level of an individual's development how may continuities and discontinuities in cultural processes impact on that person's trajectories of adaptation and maladaptation; (2) to consider how culture shapes development in general at a social (situational or contextual) and at an individual level (immediate and personal); (3) to investigate the interaction of culture with genetic, neurological, and temperamental influences; (4) to develop the measurement of cultural influence through direct assessment of culture, exploring surface- and deep-level diversity and social and individual-level processes, opening the way to improved cross-cultural translation of interventions and culturally valid assessment. Our approach fits into the second scientific concern described in this framework by proposing an evolutionarily informed developmental approach to the relationship between developmental experiences of social, epistemically valid communications and an individual's capacity to navigate and participate in the complex form of social functioning that constitutes cultural activity.

We will begin by explaining what we mean by "culture", and we will then consider thinking about the origins of human social cognition, most notably described by Tomasello. Our working definition of culture is derived from Sperber, who encapsulated it in the phrase "culture is the precipitate of cognition and communication in a human population" (Sperber, 1990, p. 42). Gergely and Csibra have described the "demand characteristics of cognitively opaque cultural forms" (Gergely \& Csibra, 2006, p. 8) as a central feature of human culture. From our standpoint this idea is also critical. Artefacts, whether in the form of abstract ideas or physical technology, that have the quality of opacity - that is, their purpose, function, 
Culture and Psychopathology

rationale or method of usage is not obvious or easily worked out without explanation from an instructor - require communication, that is, some form of education or teaching. To make the efficient learning of complex/opaque things, "humans evolve specialized cognitive resources that form a dedicated interpersonal system of mutual design in which one is predisposed to "teach" and to "learn" new and relevant cultural information to (and from) conspecifics" (Gergely \& Csibra, 2005, p. 472). This is the process of natural pedagogy which we will describe in more detail below with reference to developmental psychopathology. According to Gergely and Csibra, culture is not only the outcome of communication, it is communication - but of a particular type and purpose, deriving from natural pedagogy (Gergely \& Csibra, 2006).

Culture, as understood here, is both the process and outcome of the communication of opaque knowledge. Culture therefore can be defined as a dynamic system of explicit and implicit rules, involving attitudes, values, beliefs, traditions, customs, norms, and behaviours - a system of knowledge - shared by a relatively large group of people and passed on from generation to generation. Culture is a system that enables the accumulation and transmission of a body of shared techniques and practices to optimize people's interactions with the world around them. The primatologist, linguist and developmentalist Tomasello described the process of knowledge accumulation as 'the ratchet effect' (Tomasello, Carpenter, Call, Behne, \& Moll, 2005) - adopting new elements, which are superior to and enable us to dispense with prior solutions. This process allows the accumulation of knowledge within a community to be transmitted through interpersonal learning. Critically, social learning in this way is dependent on levels of "thinking together" - joint attention, intellectual collaboration, empathic entanglements in relation to understandings and misunderstandings - that involves interpersonal engagement and functioning at quite a sophisticated level (O’Madagain \& Tomasello, 2019; Tomasello, 2020). 
Culture and Psychopathology

Thinking together require robust and, at moments highly reflective, mentalizing. Perhaps the most persuasive understanding about how mentalizing develops is an account that centers on collaboration as an essential species-specific attribute (Tomasello, 2018). Human sociality is explained by the remarkable capacity we have to share the mental states of others. Recent research on mentalizing across species has shown surprisingly high levels of mental state understanding not just in infants, but more surprisingly in other non-human primates (Sandel, MacLean, \& Hare, 2011) and other mammals such as domestic dogs (Call, Brauer, Kaminski, \& Tomasello, 2003) and goats (Tomasello, Call, \& Kaminski, 2006). This has prompted some researchers to look more closely at what is unambiguously unique about human mentalizing. It seems that great apes can imagine and track the mental states of others; they are able to track what the other sees and even anticipate fairly accurately how this information will affect the animal's behaviour. They appear to have an understanding of mental states such as seeing, intending and knowing (Karg, Schmelz, Call, \& Tomasello, 2015).

Around nine months of age human infants, clearly capable of tracking the mental states of others (Kovacs, Teglas, \& Endress, 2010), acquire a crucial additional competence: joint attention. This is the experience when the infant and the infant's partner understand themselves to be attending to the same thing at the same time but to be doing so from different perspectives (Tomasello, 2018). Tomasello (O’Madagain \& Tomasello, 2019; Tomasello, 2019) points out that the key difference between humans and other species is this capacity to coordinate perspectives. We would suggest, along with Tomasello, that this joining of minds, in which a common object is identified at the same time as recognising different perspectives on it, is the crucial ingredient of mentalizing in humans. Tomasello describes this as a "dual level structure" of shared intentionality (Tomasello, 2020), because it encompasses both a shared focus and individual, separate perspectives upon the same thing 
Culture and Psychopathology

(Tomasello, 2016). Developmentally, as appreciation of objective reality develops, the infant and then child becomes able to triangulate the self (subjective) view, with the view of the other (the parent) concerning the same aspect of reality, and with both their own and their parent's views of the actual physical reality (Davidson, 2001). Tomasello argues that the move from epistemic tracking to shared intentionality may have been driven by the organising function of social collaboration (Tomasello, 2020). Epistemic tracking alone serves social competition well: simply knowing what the competitor wants is sufficient, and there is no great selective advantage to coordinating the competitor's mental state with the contents of one's subjectivity or indeed with external objective reality. Cooperation, however, is immeasurably advanced by being able to compare and coordinate different perspectives on the same situation (Colle et al., 2020).

Collaboration is supported by a special set of mental processes reserved for shared cognition - described as "we-mode", or relational mentalizing. A line of thinking has emerged depicting social cognition in the relational, or 'we', stance (Higgins, 2020). It is suggested that each individual who intends to accomplish some outcome together with another is requited to adopt a "first person plural perspective", the 'we-mode' (Gallotti \& Frith, 2013 p.160). The we-mode may be organized around cognitive and neural structures that are intrinsic to our individual make-up and are the product of a distinct developmental and evolutionary history (Tomasello, 2019). Building on joint intentionality, the joint agent emerges where mental states are aligned to achieve a common goal, grounded in respect born of each having a role in the collaborative activity (Tomasello, 2016). The we-mode assumes a mutual recognition of the subjectivity and humanity of the other: "recognition of the other persons as agents or persons just as real as oneself...the recognition of an inescapable fact that characterizes the human condition" (Tomasello, 2016, p. 56). 
Culture and Psychopathology

Acting jointly and collaboratively requires a distinct set of processes. The we-mode is jointly held and shared by other(s), and can be distinguished from the I-mode where the individual's beliefs, feelings and wishes are self-contained and in an ontologically separate category. In the I-mode, applying the intentional stance to others serves the self in that others are used instrumentally as social obstacles or social instruments (Tomasello, 2019). From a systemic psychotherapeutic clinical perspective we have discussed a similar set of processes under the heading of relational mentalizing (Asen \& Fonagy, 2012, 2017; Bateman \& Fonagy, 2016), referring to the shared thinking and feeling within a social system, a dyad, a family or other social group

The we-mode, or relational mentalizing, concerns intentional states that are assumed by individuals in the system to be joint or shared by everyone. It is assumed that in the "wemode" (Gallotti \& Frith, 2013), the social context (the mere presence of others) improves a person's potential for mentalizing by broadening awareness of the options available for action and generating new solutions for action. This involves co-representing the other's viewpoint, a precondition for acting jointly. When people (families or any other collection of individuals) decide to be and act together, to join forces, there is a sense in which no member of the group can be assumed to be doing it 'on their own' or can be appropriately considered as thinking or feeling in isolation from others in that 'psychological collective'. This sense of 'we-ness' of shared minds has an irreducibility which means that it must be addressed separately from individual mentalizing of self and others as joint actions are experienced in a qualitatively different way and involve shared or 'we-intentions'. This is relational mentalizing, which relies on underlying mutually accepted yet often implicit conceptual and situational presuppositions and does not necessarily involve agreement making to generate joint intention (Tuomela, 2005). 
Culture and Psychopathology

This readiness to act together, to share an action and jointly execute a plan was probably the capacity that has enabled us to conquer, if that is an appropriate term in the light of the dubious consequences of our undoubted success, all other species on the planet. The feeling associated with this joint intentionality, the feeling of We-ness, may be underpinned by and certainly generates the potential for social collaboration. This sharing of minds in an irreducibly collective mode of cognition has been recognised by many including developmentalists (e.g., Tronick, 2008), by psychoanalysts of most classical schools (e.g., Winnicott, 1956) and increasingly by neuroscientists (e.g., Gallotti \& Frith, 2013).

\section{Psychopathology as a by-product of our capacity for culture}

This thinking begins with Csibra and Gergely's theory of natural pedagogy (Csibra \& Gergely, 2009), which posits a human-specific, cue-driven social cognitive adaptation of mutual design dedicated to ensuring the most effective and efficient transfer of culturally relevant knowledge. They argue that human communication is the evolutionary product of the requirement to transmit cognitively opaque cultural knowledge: knowledge that is robust to interference, is generalizable, and becomes experienced as shared in the sense that it immediately generates an expectation that others belonging to one's social group also possess this knowledge.

Csibra and Gergely take the concept of "ostensive cues" (Csibra \& Gergely, 2009) (Csibra \& Gergely, 2011) - discussed originally by Bertrand Russell (1940/1967), but extensively used by Sperber and Wilson (1995) - to mean that certain signals are employed by an agent and prepare the addressee for the intent of the agent to communicate. Examples of ostensive cues are eye contact, eyebrow raising, contingent reactivity and infant-direct speech ("motherese"). Ostensive cues may also serve the function of counteracting natural "epistemic vigilance" - the self-protective suspicion towards potentially damaging, 
Culture and Psychopathology

deceptive, or inaccurate information (Sperber et al., 2010). Ostensive cues generate a particular attentional state, which we link to the we-mode discussed above, where epistemic vigilance is momentarily suspended and the addressee feels that the subsequent communication contains information specifically relevant to them which should be remembered and encoded as knowledge relevant generally to social situations involving the self with others (Butler, Gibbs, \& Levush, 2020; Gergely, 2013). Such information can be about an object, or about the other's views and attitudes about the object or indeed the beliefs communicated by the other about the self that can be regarded as generalizable and relevant across situations (Egyed, Király, \& Gergely, 2013; Futo, Teglas, Csibra, \& Gergely, 2010). The information can be laid down and used as part of procedural and semantic memory, not uniquely or primarily episodic memory (Kovacs, Teglas, Gergely, \& Csibra, 2017).

We have found the notion of ostensive cues helpful as it links directly to our understanding of the we-mode of social cognition. To learn about reality, we have to turn to others. The human world, outside and inside, is so complex that it is impossible to discover it all by ourselves. We also learn about ourselves from others. We build and constantly unconsciously update representations of ourselves through our social interactions imbued with learning opportunities (Gergely \& Jacob, 2012; Gopnik \& Wellman, 2012). The knowledge we acquire about who we are does not emerge from within but is absorbed from others, kept current, updated in response to changing social contexts, enabling social adaptation crucial to human survival. Throughout development, the key to keeping the learning channel open is the experience of self-recognition that ideally precedes genuine learning from the object. That experience is based on detecting how one is seen. By its very nature, this assessment of how one's mind is being seen by another must be highly contingent on the feedback one is receiving from the other. This allows for highly responsive and adaptive social learning about the particular nature of the social environment, and as such it 
Culture and Psychopathology

generates the particular flexibility of human social cognition. But it also, we suggest, creates a potential vulnerability in terms of psychopathology.

The theory of natural pedagogy underlines the highly interpersonal nature of the process by means of which epistemic trust - trust in communicated information - is generated in infancy, and this has significant implications for the field of developmental psychopathology. Associative learning assessed early in development appears predictive of later social functioning (Reeb-Sutherland, Levitt, \& Fox, 2012) and learning strategies emerging early in infancy may come to significantly influence behaviour in complex social situations (Hammock \& Levitt, 2006). Caregiving experiences affect how someone extracts and processes information from the environment and learning capacity is influenced by an individual's caregiving history. This has been classically shown for macaques (Capitanio, 1985; Mason \& Capitanio, 1988) and also for human infants (Bigelow \& DeCoste, 2003). Less contingently responsive caregiving is associated with slower rates of associative learning in infants (Papousek \& Papousek, 1975). We suggest that if the caregivers around the infant are not reliably responsive, not benign and/or not able to recognise what is meaningful and relevant to the infant's self, this can undermine the capacity to learn through the underdevelopment of epistemic trust. There is evidence that the quality of the relationship of a child to a communicator determines in large measure the extent to which the child will acquire information from that communicator and generalize this (Corriveau et al., 2009; Lane \& Harris, 2015; Mascaro \& Sperber, 2009; Shafto, Eaves, Navarro, \& Perfors, 2012). This emphasis on the significance of reputation within interpersonal processes is in keeping with recent work exploring the inherently socially driven nature of higher order cognitive processes (Rudrauf, 2014).

Our hypothetical model for social learning moderated by epistemic trust would be assumed to be contingent on the establishment of the we-mode. The we-mode may come to 
Culture and Psychopathology

characterise the learning situation through any one of the we-processes we described but the prototypical path might be: (1) the learner's imagined sense of self (their personal narrative) (2) is imagined by the instructor establishing a prospect for the we-mode and (3) this image is perceived reinforcing the potential we-mode and (4) compared with the learner's personal narrative and (5) in case of a match the co-representation has been created, the we-mode removes the I-mode's protection from change and the channel for rapid, efficient knowledge transfer is opened. Relational mentalising is thus key to establishing epistemic trust. The communicator needs to be able to mentalize the addressee well enough for the addressee to feel accurately mentalized. This imaginative experience (we-mode) unlocks the barrier epistemic of vigilance. Throughout development the key to keeping the learning channel open is generating experiences of recognition that enables genuine learning from the communicator. That experience is based on detecting how one is seen - what we term the epistemic match. Putting it at its pragmatic simplest: if I feel that I am understood, I will be disposed to learn from the person who understood me, who I feel is a trustworthy potential collaborator. This will include learning about myself but also learning about others and about the world I live in.

Our developmental, interpersonal view on the stimulation of epistemic trust in the context of early relationships creates a new role for the attachment relationship. We propose that human social-cognitive developmental processes have hijacked the attachment relationship to use it as one, though not the only, major mediator of epistemic trust. One of the great social advantages bestowed by secure attachment, we suggest, is that it promotes the individual's capacity for social learning because it facilitates a general capacity for epistemic trust (Luyten, Campbell, Allison, \& Fonagy, 2020b) and may account for some of the benefit which secure attachment brings in terms of mental health benefit (Groh, Fearon, van IJzendoorn, Bakermans-Kranenburg, \& Roisman, 2017). Research evidence supports the 
Culture and Psychopathology

developmental nature of trust and the social factors that influence it (Corriveau et al., 2009; Eaves \& Shafto, 2017; Markson \& Luo, 2020; Tong, Wang, \& Danovitch, 2020).

The attachment relationship constitutes a powerful source of social information about the environment and the extent to which a strong orientation towards other people's mental states may be an appropriate strategy (Fonagy \& Campbell, 2017a). The great gift of a secure attachment relationship when considered in relation to groups not just individuals (Hrdy, 2006, 2009, 2013; Mesman, Minter, \& Angnged, 2016; Mesman et al., 2018; Mesman, van IJzendoorn, et al., 2016) is that it enables the child to orient themselves to opportunities for cultural learning from their environment (Fonagy, Luyten, Allison, \& Campbell, 2017a, 2017b). This idea is embodied in Tomasello's (2016) proposal of collective intentionality, a form of shared intentionality where the child comes to coordinate their actions with an increasingly large group that ultimately becomes our culture. Ultimately, this enables us to communicate with, learn from and collaborate with, non-kin who are around us because we share with them a sense of identity obtained through common practices, beliefs, attitudes and a sense of belonging or identity.

This is not to negate the importance of dyadic approaches to attachment. Caregiver sensitivity is likely to be teaching the child to be sensitive to ostensive cues that trigger the joint intentionality of the we-mode and may be a part of the explanation of the educational advantages which secure attachment brings (J. Belsky \& Fearon, 2002; Stievenart, Roskam, Meunier, \& Van de Moortele, 2011; van IJzendoorn, Dijkstra, \& Bus, 1995). We would argue that sensitivity serves to instil 'basic trust' that a caregiver can function with synchronous behaviour to the infant and reliably establish shared intentionality by a variety of means involving creating (for the child) a perceptible representation of their self-narrative which generates a co-representation of sufficient clarity to engender the epistemic trust necessary to explore, establish joint intentionality and learn from the caregiver and from others and re- 
Culture and Psychopathology

establish the safe haven of the we-mode when returning in need of comfort or support. Of course, the we-mode ensures that the infant learns about themselves (their emotions, their thinking and their identity) from the safe instruction of the caregiver. Thus sensitivity fostering secure attachment also fosters the capacity for social learning and adaptations across cultures. Recently, Mesman and colleagues demonstrated cross-cultural relevance of sensitivity showing that it could be reliably coded on the basis on interactions in seven different cultures.

Dyadic sensitivity generating a predisposition to epistemic trust is unlikely to be an exclusive strategy by which this social orientation can be achieved. Many non-Western communities have simultaneous multiple caregiving without clear place-bound or time-bound task division (Hrdy, 2009). Anthropological studies consistently describe the wide prevalence of collectively distributed alloparenting - infants receiving person-directed care from a range of caregivers - engendering multiple natural attachments (Hrdy, 2016; Marlowe, 2005; Meehan \& Hawks, 2015). Looking for a predefined characterisation such as sensitivity of dyadic interactions in cultural context is known as the etic approach to studying behavior and is contrasted with the emic approach that takes each culture as its own starting point (Harris, 1976). Taking the emic approach, sensitivity has a different timbre in non-Western cultures. It is not that environments do not differ in terms of the amount of security they provide but this is a function of the social network which is foundational to the child's development (Meehan, Helfrecht, \& Malcom, 2016). Even when there is proximal caregiving for the infant from a carer, the child is metaphorically 'facing outward', their priority is to learn to see the world as others see it. Caregivers orient children literally outward by placing them in the same direction in which they are facing (Ochs \& Izquierdo, 2009); they lead them in activity and children follow their lead (Keller, Kartner, Borke, Yovsi, \& Kleis, 2005). Thus the carer's priority is not to demonstrate knowledge about and teach the infant about the self but 
Culture and Psychopathology

rather to support them to take the perspective of others. Non-Western adult-child play and talk tend to be less common and when they do take place, they usually do not follow the typical interactional "script" of Western lifestyle communities. Indeed, face-to-face serveand-respond interaction may be a somewhat anomalous form of ostensive cueing in human evolutionary experience (Keller \& Bard, 2017; Keller \& Chaudhary, 2017). There are many ways that a child can have their agency recognised that do not follow the Western model of parental interaction. Care may be less psychological or even emotion focused and far more based on physical contact (Morelli et al., 2017). The caregiver speaks to the infant not about them but rather to instruct, guide and direct them to appreciate understanding the actions of others. The infant is a 'social apprentice' who only learns secondarily about self by identifying the ways their experience is similar to those of others in the community. While this care might not appear to fall in with some of the one-on-one interactive sensitive caregiving, and what is critical for security and trust is likely to be culture specific (Keller \& Chaudhary, 2017), what it does provide is a powerful piece of interpersonal communication about the capacity of the environment to accommodate and be oriented to one's presence (Fonagy \& Campbell, 2017b). The nature of that communication creates moments of recognition and sense of joint intentionality albeit these are experienced in the context of the social network and privilege behaviours that are most likely to ensure security in that community.

One-to-one sensitive responsiveness from a primary caregiver is one route to establishing we-mode and epistemic trust, but there are other routes. The we-mode can be as readily created around a joint intention to explore others, jointly seeing to it to see how others feel. Epistemic trust might in many cultures be affectively isomorphic with attachment (particularly in normative Westernised cultures), but epistemic trust and attachment may also be two separate developmental processes. Indeed, dyadic sensitivity may be a somewhat 
Culture and Psychopathology

anomalous form of ostensive cueing of the we-mode in human evolutionary experience (Keller et al., 2018). There are many ways that a child can have their interest and agency recognised that do not follow Ainsworth's model of infant-parent interaction. For example, the young child's experiences of having their physical needs met, discomforts resolved and their desire to explore tolerated, may not involve any conventional sensitive interaction. It may not involve the same caregiver, can engage a broader social group with an investment in the child, it may not involve conversation, or even eye contact, there may be little overt acknowledgement or much of a pause while pursuing other tasks - but such interactions can still generate a powerful experience of having one's "knowledge" (what I perceive myself to need) affirmed and shown to be aligned with what the social environment can provide and tolerate (the experience of having those needs met) (Keller et al., 2018; Keller \& Chaudhary, 2017). Commentary on psychological states (mind-mindedness) is one way caregivers may align intentional stances, supporting early motor independence may be another. It is engagement in collaboration and shared intentionality that underpins the we-mode and it is epistemic trust that ensures that social learning can take place as the I-mode is replaced by the we-mode.

In focusing on social learning we see vulnerable or sensitive developmental periods stretching beyond the early years into later childhood and adolescence. Critically, these are the times when children and young people, through school and ever-widening exposure to the outside world, have their perceptions of the world as safe and reliable, or dangerous and unpredictable, reinforced. Whilst early attachment increases the chances of a positive outcome (Simpson, Collins, Tran, \& Haydon, 2007), peer, not parental, support and acceptance turns out to be the best predictor of resilience in adolescence (van Harmelen et al., 2017). Yet the mechanisms we identify in the context of studying early development may indeed be of great help in understanding later influences. Shared intentionality will be or will 
Culture and Psychopathology

fail to be established with a range of agents. Further, epistemic trust can be understood, on a heuristic level at least, as a generalized trust in one's social community: shared intentionality may be experienced by the individual at a group as well as on an individual level, and is related to the expectation that the social environment will protect, care for and help realize aims and ambitions.

It is clear that the absence of epistemic trust would deeply disadvantage an individual in many social contexts. The loss of this key process for the efficient acquisition of selfknowledge as part of cultural knowledge has significant implications for social functioning. The individual may become limited in their ability to update their understanding of potentially rapidly changing social situations and would appear inflexible or even rigid in the face of social change. Why would an individual fail to experience epistemic trust even in situations where trust was warranted - that is, where their personal narrative was appreciated? There are two obvious reasons. First, adversity and deprivation, when tantamount to trauma, can generate chronic mistrust by inhibiting imagination, creating an overarching avoidance of thinking about either one's own or other people's mental states, leaving the individual deeply vulnerable in most social situations (Ensink et al., 2015; Levy, Goldstein, \& Feldman, 2019; Macintosh, 2013; Taubner \& Curth, 2013). Even in the absence of such a pervasive failure of imagination, a compromised capacity to mentalize, that is, to make sense of both other people's behavior in terms of underlying mental states, may lead the traumatized individual to be biased in their perception of social reality (Cicchetti \& Curtis, 2005; Germine, Dunn, McLaughlin, \& Smoller, 2015; Kay \& Green, 2016) and misrepresent how others represent them, leading them to feel persistently misunderstood and to experience an intense and consistent sense of injustice. Secondly, the long-term outcome of epistemic isolation secondary to the failure of imagination we describe here may create problems for individuals who have distorted personal narratives that generate inaccurate views of the self, so that even 
Culture and Psychopathology

an accurate perception of one's personal narrative by others is not experienced as a match, and a painful experience of interpersonal alienation persists. For example, an individual whose personal narrative entails a sense of failure or badness will not paradoxically benefit from a supportive, positive reflection of their self-narrative, and are left with a sense of not having been understood. Conversely, in yet other instances, deprivation and trauma may generate inappropriate trust. We understand such excessive epistemic credulity as triggered by a hyperactive or unmoored social imagination generating a personal narrative that is too diffuse to provide an accurate sense of differential awareness of others' capacity to perceive oneself. Excessive credulity results as all personal narratives feel as if they "fit" sufficiently for trust to be generated, making the person vulnerable to exploitation. Of course, limited imagination may cause profound misperceptions of the other's representations of one's personal narrative, and an illusory fit is created where none in reality exists. There may be many other possibilities.

If epidemiological figures are to be relied on, only one in five people will go through life without experiencing a diagnosable mental health condition (Schaefer et al., 2017): perhaps it is mental health rather than mental illness that is something of a myth (Szasz, 1960). Looking at such prevalence figures from the perspective of natural selection, it is clear that whatever the neural systems are that underpin mental disorder, they must have other functions that are critical for survival. A defining feature of mental disorder is the experience of "wild imagination". Human imagination is essential for mentalizing, and hence for the transmission of culture. We need to be able to imagine others' perspectives to collaborate effectively in a social world, which seems to be a small price to pay for the errors - or wildness - of imagination that can ensue following adversity or trauma

Carver et al (Carver, Johnson, \& Timpano, 2017) have helpfully drawn attention to the contrast between reflective and reflexive mode of cognition suggested by Epstein (1994) 
Culture and Psychopathology

to delineate a dichotomy between a basic, responsive to emotion mode (reflexive) and deliberative mental function (reflective). A claimed shared characteristic of the reflexive mode is relative spontaneity, simplicity and responsiveness to affect (Metcalfe \& Mischel, 1999; Strack \& Deutsch, 2004). There is inherent uncertainty to social communication because of the ultimate opaqueness of other minds. Thus a reflexive mode of functioning may be better adapted to the task of establishing joint intentionality especially in human environments dominated by uncertainty. Yet if emotions are responded to spontaneously, without constraint, the individual may be at risk or vulnerable to mental disorder (Carver et al., 2017). The idea that different modes of cognition might be triggered by the environment, and how this might interact with an individual's stance on social learning will be explored further in the final section of this paper to consider the risk factors for psychopathology arising from socio-economic circumstances..

\section{Reintegrating the social environment with the key questions of psychopathology}

How does the social learning/epistemic trust model help us understand the profound influence of the social environment - in particular economic deprivation or exposure to discrimination, social isolation or a hostile community - on child development and the emergence of mental health problems. We assume that such social environments can signal to the child that they are not facing a reliable, safe environment in which it is adaptive to be trusting and open to social learning (Luyten et al., 2020a). There is now good evidence supporting these assumptions.

The Five Year Forward View for Mental Health recognized that children from low income families are at three times higher risk of mental health problems than those from the highest income families (NHS England, 2014), and the recent survey of the prevalence of 
Culture and Psychopathology

diagnosable mental disorder in children and young people in England found that mental disorders occurred more commonly in children living in low income households (NHS Digital, 2018). In this survey, other factors that increased the likelihood of diagnosable disorder included having parents who showed signs of common mental health problems and living in families with less healthy family functioning. Maternal depression and couple conflict are also associated with economic pressure (Kavanaugh, Neppl, \& Melby, 2018) and the impact of these factors on young people's mental health has been conceptualized in terms of the Family Stress Model: economic hardship puts economic pressure on families, leading to parental psychological distress which results in both interparental relationship problems and disrupted parenting, ultimately leading to adjustment problems in children and young people (Masarik \& Conger, 2017). Help with these difficulties is likely to be less available to lower income families and lower SES has been shown to be associated with poorer care for mental health problems generally (Jokela, Batty, Vahtera, Elovainio, \& Kivimaki, 2013).

Other suggested mediators of the impact of low socio-economic status on mental health outcomes for children and young people include stressful life events, literacy difficulties and the experience of living in a disadvantaged neighbourhood (Piotrowska, Stride, Maughan, \& Rowe, 2019). It can be difficult to disentangle family and neighbourhood level effects of disadvantage, although it has been suggested that as children's autonomy and independence from their caregivers increase, they are likely to be more exposed to potential direct neighbourhood effects on development, which have been hypothesized to include increased likelihood of interaction with antisocial peers, lack of access to social facilities, tensions between majority and minority residents, relative lack of mechanisms of social control and low levels of cohesion, support and collective efficacy (Ingoldsby et al., 2006) as well as awareness of income differentials (Wilkinson \& Pickett, 2009). 
Culture and Psychopathology

However, it is important not to make simplistic assumptions about the quality of relationships implied by socio-economic disadvantage. It has also been shown that highsocioeconomic status individuals feel more powerful and manifest cognitive and behavioral tendencies with a greater focus on self (Inesi, Botti, Dubois, Rucker, \& Galinsky, 2011). By contrast, individuals with low-socioeconomic status feel relatively less powerful and manifest tendencies with a greater focus on others and the community they are in. In other words high SES individuals have a focus on the I-mode driven by personal agency, while low power, low SES individuals are more likely to have a communal focus and prioritise we-processes (Rucker \& Galinsky, 2017). Individuals who are less socio-economically privileged tend to behave in more community and socially oriented ways in interpersonal trust experiments and tend to spend more money proportionately on social activities and charity than more affluent individuals (Dubois, Rucker, \& Galinsky, 2015). Less affluent individuals are more dependent on their community; wealthier and more socially protected individuals have a stronger perception of their self-agency and do not need to be so community focused (Overbeck \& Droutman, 2013). As a result, individuals functioning in a lower SES environment are also likely to be more sensitive to their social environment and its reliability and how benign or supportive it may be (Gruenfeld, Inesi, Magee, \& Galinsky, 2008; Liu et al., 2017). This greater orientation towards the community places individuals who lack power at greater risk when they encounter hostile social contexts and explicit adversity. Thus, whether the impact of deprivation is felt via the reduction of social trust or if the lack of individual power of members in the high deprivation social groups places them in positions of greater vulnerability when social networks break down, the prediction would be for a linear relationship between socio-economic disadvantage and poor mental health outcomes.

When children live in such social contexts, high-risk life strategies (Del Giudice, 2016), as generated by imaginative solutions that may bear little on objective reality, could be 
Culture and Psychopathology

more advantageous than solutions arrived at through more exhaustive logical inference.

Along with others, we have suggested that the quality of family relationships in an attachment context in early life may provide the child with information about the safety or predictability of their environment (Chisholm, 1999). Creative solutions inevitably entail high risk and are most likely to be adaptive in the context of unpredictable environments (Frankenhuis \& Del Giudice, 2012). This is simply a reflection of how natural selection shapes developmental strategies that in turn give rise to phenotypes adapted to a local ecology (Panchanathan, Frankenhuis, \& Barrett, 2010). A possible general model for psychopathology is provided by the notion of a developmental mismatch (Gluckman, Low, Buklijas, Hanson, \& Beedle, 2011). A change of environment might create problems of a developmental mismatch. Thus, the prioritization of reflexive cognition indicated by hostile early environmental conditions might actually generate maladaptive responses under more favorable conditions.

So why is there more mental disorder in low-SES communities? It is not at all improbable that if dependence on the community is greater in less powerful individuals, then losing that support through the breakup or fragmentations of the social fabric will impact more on an low than high SES individuals. Failure of epistemic trust will affect low-SES people more than high-SES people because low-SES individuals are more dependent on their community. If resilience is maintaining We-ness, joint intentionality, the openness to social learning and epistemic trust embedded into the links with the community then the individual who is more dependent on those links because of their relative lack of power will be more likely to succumb to mental disorder than the individual whose position of power enables them to act as independent agents.

A further characteristic of uncertain and adverse environments is that they trigger reflexive thinking, and with it spontaneity and imagination both to find imaginative solutions 
Culture and Psychopathology

and to optimise the chance of establishing joint intentionality with individuals who could be a source of support through joint action. In adversity, imaginative solutions that may bear little on objective reality could be more advantageous than solutions arrived at through more exhaustive logical inference (Frankenhuis \& Del Giudice, 2012). This has been suggested as the evolutionary basis of the risky strategies commonly generated by adolescents characteristic of young people under environmental pressure (Del Giudice, 2016). Congruent with this, our work has also demonstrated that maladaptive solutions at this developmental period are characterised by an unconstrained excess of mentalising that Carla Sharp and colleagues have termed hypermentalizing (Sato, Fonagy, \& Luyten, 2018). Thus, the prioritization of reflexive cognition indicated by hostile early environmental conditions might generate adaptive responses under favourable conditions, but could also increase the risk of profoundly maladaptive developments. If calling forth imagination is a double edged sword, bringing a risk of imagination unconstrained by objectivity, perhaps it is unsurprising that children are most at risk of mental disorder when they grow up in adverse environments in the absence of social support and the potential of binding unconstrained imagination within an agreed social reality. We speculate that the epistemic trust that the experience of being mentalized may act to regulate imaginative mentalizing activity. Perhaps, the benefit of social support may rest in the assurance that if a young person feels they have found joined intentionality with concerned others, they do not need to expend excessive efforts to understand themselves, and the experience of trust can provide a secure platform that enables them to turn outwards to others in their social world. 
Culture and Psychopathology

\section{References}

Alnæs, D., Kaufmann, T., Doan, N. T., Córdova-Palomera, A., Wang, Y., Bettella, F., ... Westlye, L. T. (2017). Heritable cognitive and psychopathology factors in youth are predicted by brain fronto-temporal white matter pathway. bioRxiv.

American Psychiatric Association. (2013). Diagnostic and statistical manual of mental disorders, 5th edn (5th ed.). Washington, DC: American Psychiatric Association.

Asen, E., \& Fonagy, P. (2012). Mentalization-based therapeutic interventions for families. Journal of Family Therapy, 34(4), 347-370.

Asen, E., \& Fonagy, P. (2017). Mentalizing family violence part 1: Conceptual framework. Family Process, 56(1), 6-21.

Bateman, A., \& Fonagy, P. (2013). Impact of clinical severity on outcomes of mentalisationbased treatment for borderline personality disorder. British Journal of Psychiatry, 203(3), 221-227.

Bateman, A., \& Fonagy, P. (2016). Mentalization-based treatment for personality disorders: A practical guide (2nd ed.). Oxford, UK: Oxford University Press.

Beauchaine, T. P., \& Cicchetti, D. (2016). A new generation of comorbidity research in the era of neuroscience and Research Domain Criteria. Development and Psychopathology, 28(4pt1), 891-894.

Beauchaine, T. P., \& Thayer, J. F. (2015). Heart rate variability as a transdiagnostic biomarker of psychopathology. International Journal of Psychophysiology, 98(2 Pt 2), 338-350.

Belsky, D. W., Caspi, A., Arseneault, L., Corcoran, D. L., Domingue, B. W., Harris, K. M., . .. Odgers, C. L. . (2019). Genetics and the geography of health, behaviour and attainment. Nature Human Behaviour, 3(6), 576-586. 
Culture and Psychopathology

Belsky, J., \& Fearon, R. M. (2002). Infant-mother attachment security, contextual risk, and early development: a moderational analysis. Development and Psychopathology, 14(2), 293-310.

Bigelow, A. E., \& DeCoste, C. (2003). Infants' sensitivity to contingency in social interactions with familiar and unfamiliar partners. Infancy, 4, 111-140.

Blanco, C., Wall, M. M., Hoertel, N., Krueger, R. F., Liu, S. M., Grant, B. F., \& Olfson, M. (2019). Psychiatric disorders and risk for multiple adverse outcomes: A national prospective study. Molecular Psychiatry.

Bloemen, A. J. P., Oldehinkel, A. J., Laceulle, O. M., Ormel, J., Rommelse, N. N. J., \& Hartman, C. A. (2018). The association between executive functioning and psychopathology: General or specific? Psychological Medicine, 48(11), 1787-1794.

Bonifay, W., \& Cai, L. (2017). On the complexity of item response theory models. Multivariate Behavioral Research, 52(4), 465-484.

Bornovalova, M. A., Choate, A. M., Fatimah, H., Petersen, K. J., \& Wiernik, B. M. (2020). Appropriate use of bifactor analysis in psychopathology research: Appreciating benefits and limitations. Biological Psychiatry, 88(1), 18-27.

Brainstorm Consortium, Anttila, V., Bulik-Sullivan, B., Finucane, H. K., Walters, R. K., Bras, J., . . Murray, R. (2018). Analysis of shared heritability in common disorders of the brain. Science, 360(6395).

Bronfenbrenner, U. (1979). The ecology of human development: Experiments by nature and design. Cambridge, MA: Harvard University Press.

Budde, M., Anderson-Schmidt, H., Gade, K., Reich-Erkelenz, D., Adorjan, K., Kalman, J. L., ... Heilbronner, U. (2018). A longitudinal approach to biological psychiatric research: The PsyCourse study. American Journal of Medical Genetics Part B: Neuropsychiatric Genetics. 
Culture and Psychopathology

Butler, L., Gibbs, H., \& Levush, K. (2020). Look again: Pedagogical demonstration facilitates children's use of counterevidence. Child Development, 1-17.

Call, J., Brauer, J., Kaminski, J., \& Tomasello, M. (2003). Domestic dogs (Canis familiaris) are sensitive to the attentional state of humans. Journal of Comparative Psychology, 117(3), 257-263.

Capitanio, J. P. (1985). Early experience and social processes in rhesus macaques (Macaca mulatta): II. Complex social interaction. Journal of Comparative Psychology, 99(2), 133-144.

Carragher, N., Teesson, M., Sunderland, M., Newton, N. C., Krueger, R. F., Conrod, P. J., . . . Slade, T. (2016). The structure of adolescent psychopathology: A symptom-level analysis. Psychological Medicine, 46(5), 981-994.

Carver, C. S., Johnson, S. L., \& Timpano, K. R. (2017). Toward a functional view of the p factor in psychopathology. Clinical Psychological Science.

Caspi, A., Houts, R. M., Belsky, D. W., Goldman-Mellor, S. J., Harrington, H., Israel, S., . . . Moffitt, T. E. (2014). The p factor: One general psychopathology factor in the structure of psychiatric disorders? Clinical Psychological Science, 2(2), 119-137.

Caspi, A., \& Moffitt, T. E. (2018). All for one and one for all: Mental disorders in one dimension. American Journal of Psychiatry, 175(9), 831-844.

Castellanos-Ryan, N., Briere, F. N., O'Leary-Barrett, M., Banaschewski, T., Bokde, A., Bromberg, U., . . Consortium, I. (2016). The structure of psychopathology in adolescence and its common personality and cognitive correlates. Journal of Abnormal Psychology, 125(8), 1039-1052.

Causadias, J. M. (2013). A roadmap for the integration of culture into developmental psychopathology. Dev Psychopathol, 25(4 Pt 2), 1375-1398. 
Culture and Psychopathology

Causadias, J. M., \& Cicchetti, D. (2018). Cultural development and psychopathology. Dev Psychopathol, 30(5), 1549-1555.

Chisholm, J. S. (1999). Attachment and time preference: Relations between early stress and sexual behavior in a sample of American university women. Human Nature, 10(1), $51-83$.

Cicchetti, D., \& Curtis, W. J. (2005). An event-related potential study of the processing of affective facial expressions in young children who experienced maltreatment during the first year of life. Development and Psychopathology, 17(3), 641-677.

Cirino, P. T., Ahmed, Y., Miciak, J., Taylor, W. P., Gerst, E. H., \& Barnes, M. A. (2018). A framework for executive function in the late elementary years. Neuropsychology, 32(2), 176-189.

Colle, L., Dimaggio, G., Carcione, A., Giuseppe, N., Semerari, A., \& Chiavarino, C. (2020). Do competitive contexts affect mindreading performance? Frontiers in Psychology

Constantinou, M., \& Fonagy, P. (2019). Evaluating bifactor models of psychopathology using model-based reliability indices. PsyArXiv Preprints. 10.31234/osf.io/6tf7j.

Copeland, W. E., Shanahan, L., Erkanli, A., Costello, E. J., \& Angold, A. (2013). Indirect comorbidity in childhood and adolescence. Frontiers in Psychiatry, 4, 144.

Corriveau, K. H., Harris, P. L., Meins, E., Fernyhough, C., Arnott, B., Elliott, L., . . . de Rosnay, M. (2009). Young children's trust in their mother's claims: Longitudinal links with attachment security in infancy. Child Development, 80(3), 750-761.

Crittenden, B. M., Mitchell, D. J., \& Duncan, J. (2016). Task encoding across the multiple demand cortex is consistent with a frontoparietal and cingulo-opercular dual networks distinction. Journal of Neuroscience, 36(23), 6147-6155. 
Culture and Psychopathology

Cross-Disorder Group of the Psychiatric Genomics Consortium. (2013). Identification of risk loci with shared effects on five major psychiatric disorders: a genome-wide analysis. Lancet, 381(9875), 1371-1379.

Csibra, G., \& Gergely, G. (2009). Natural pedagogy. Trends in Cognitive Sciences, 13(4), $148-153$.

Csibra, G., \& Gergely, G. (2011). Natural pedagogy as evolutionary adaptation. Philosophical Transactions of the Royal Society of London. Series B, Biological Sciences, 366(1567), 1149-1157.

Davidson, D. (2001). Subjective, intersubjective, objective. Oxford, UK: Clarendon Press.

Del Giudice, M. (2016). The life history model of psychopathology explains the structure of psychiatric disorders and the emergence of the $\mathrm{p}$ factor. Clinical Psychological Science, 4(2), 299-311.

Delfin, C., Andine, P., Hofvander, B., Billstedt, E., \& Wallinius, M. (2018). Examining associations between psychopathic traits and executive functions in incarcerated violent offenders. Frontiers in Psychiatry, 9, 310.

Demetriou, E. A., Lampit, A., Quintana, D. S., Naismith, S. L., Song, Y. J. C., Pye, J. E., . . . Guastella, A. J. (2018). Autism spectrum disorders: A meta-analysis of executive function. Molecular Psychiatry, 23(5), 1198-1204.

DeRubeis, R. J., Gelfand, L. A., Tang, T. Z., \& Simons, A. D. (1999). Medications versus cognitive behavior therapy for severely depressed outpatients: Mega-analysis of four randomized comparisons. American Journal of Psychiatry, 156, 1007-1013.

Deutz, M. H. F., Geeraerts, S. B., Belsky, J., Dekovic, M., van Baar, A. L., Prinzie, P., \& Patalay, P. (2020). General psychopathology and dysregulation profile in a longitudinal community sample: Stability, antecedents and outcomes. Child Psychiatry and Human Development, 51(1), 114-126. 
Culture and Psychopathology

Diamond, A. (2013). Executive functions. Annual Review of Psychology, 64, 135-168.

Dickson, H., Cullen, A. E., Jones, R., Reichenberg, A., Roberts, R. E., Hodgins, S., . . . Laurens, K. R. (2018). Trajectories of cognitive development during adolescence among youth at-risk for schizophrenia. Journal of Child Psychology and Psychiatry, 59(11), 1215-1224.

Dolan, M. (2012). The neuropsychology of prefrontal function in antisocial personality disordered offenders with varying degrees of psychopathy. Psychological Medicine, $42(8), 1715-1725$.

Drabick, D. A., Ollendick, T. H., \& Bubier, J. L. (2010). Co-occurrence of ODD and anxiety: Shared risk processes and evidence for a dual-pathway model. Clinical Psychology: Science and Practice, 17(4), 307-318.

Dubois, D., Rucker, D., \& Galinsky, A. (2015). Social class, power, and selfishness: When and why upper and lower class individuals behave unethically. Journal of Personality and Social Psychology, .108(3), pp.

Dunner, D. L., Lipschitz, A., Pitts, C. D., \& Davies, J. T. (2005). Efficacy and tolerability of controlled-release paroxetine in the treatment of severe depression: Post hoc analysis of pooled data from a subset of subjects in four double-blind clinical trials. Clinical Therapeutics, 27(12), 1901-1911.

Eaves, B. S., Jr., , \& Shafto, P. (2017). Parameterizing developmental changes in epistemic trust. Psychonomic Bulletin \& Review, 24(2), 277-306.

Egyed, K., Király, I., \& Gergely, G. (2013). Communicating shared knowledge without language in infancy. Psychological Science, 24(7), 1348-1353.

Elkin, I., Gibbons, R. D., Shea, M. T., Sotsky, S. M., Watkins, J. T., Pilkonis, P. A., \& Hedeker, D. (1995). Initial severity and differential treatment outcome in the National 
Culture and Psychopathology

Institute of Mental Health Treatment of Depression Collaborative Research Program. Journal of Consulting and Clinical Psychology, 63(5), 841-847.

Elliott, M. L., Romer, A., Knodt, A. R., \& Hariri, A. R. (2018). A connectome-wide functional signature of transdiagnostic risk for mental illness. Biological Psychiatry, 84(6), 452-459.

Ensink, K., Normandin, L., Target, M., Fonagy, P., Sabourin, S., \& Berthelot, N. (2015). Mentalization in children and mothers in the context of trauma: An initial study of the validity of the Child Reflective Functioning Scale. British Journal of Developmental Psychology, 33(2), 203-217.

Epstein, S. (1994). Integration of the cognitive and the psychodynamic unconscious. American Psychologist, 49(8), 709-724.

Ernst, M., Mohr, H. M., Schott, M., Rickmeyer, C., Fischmann, T., Leuzinger-Bohleber, M., . . Grabhorn, R. (2018). The effects of social exclusion on response inhibition in borderline personality disorder and major depression. Psychiatry Research, 262, 333339.

Feinstein, A. R. (1970). The pre-therapeutic classification of co-morbidity in chronic disease. Journal of Chronic Diseases, 23(7), 455-468.

Fonagy, P., \& Campbell, C. (2017a). Bad blood: 15 years on. Psychoanalytic Inquiry, 37(5), 281-283.

Fonagy, P., \& Campbell, C. (2017b). What Touch Can Communicate: A Commentary on Mentalizing Homeostasis. Neuropsychoanalysis, 19(1), 39-42.

Fonagy, P., \& Luyten, P. (2009). A developmental, mentalization-based approach to the understanding and treatment of borderline personality disorder. Development and Psychopathology, 21(4), 1355-1381. 
Culture and Psychopathology

Fonagy, P., Luyten, P., Allison, E., \& Campbell, C. (2017a). What we have changed our minds about: Part 1. Borderline personality disorder as a limitation of resilience. Borderline Personality Disorder and Emotion Dysregulation, 4, 11.

Fonagy, P., Luyten, P., Allison, E., \& Campbell, C. (2017b). What we have changed our minds about: Part 2. Borderline personality disorder, epistemic trust and the developmental significance of social communication. Borderline Personality Disorder and Emotion Dysregulation, 4, 9.

Fonagy, P., Twemlow, S. W., Vernberg, E. M., Nelson, J. M., Dill, E. J., Little, T. D., \& Sargent, J. A. (2009). A cluster randomized controlled trial of child-focused psychiatric consultation and a school systems-focused intervention to reduce aggression. Journal of Child Psychology and Psychiatry, 50(5), 607-616.

Forbes, M. K., Tackett, J. L., Markon, K. E., \& Krueger, R. F. (2016). Beyond comorbidity: Toward a dimensional and hierarchical approach to understanding psychopathology across the life span. Development and Psychopathology, 28(4pt1), 971-986.

Frankenhuis, W. E., \& Del Giudice, M. (2012). When do adaptive developmental mechanisms yield maladaptive outcomes? Developmental Psychology, 48(3), 628642.

Freud, S. (1930). Civilization and its discontents. In J. Strachey (Ed.), The standard edition of the complete psychological works of Sigmund Freud (Vol. 21, pp. 57-146). London, UK: Hogarth Press, 1961.

Friedman, N. P., \& Miyake, A. (2017). Unity and diversity of executive functions: Individual differences as a window on cognitive structure. Cortex, 86, 186-204.

Futo, J., Teglas, E., Csibra, G., \& Gergely, G. (2010). Communicative function demonstration induces kind-based artifact representation in preverbal infants. Cognition, 117(1), 1-8. 
Culture and Psychopathology

Gallotti, M., \& Frith, C. D. (2013). Social cognition in the we-mode. Trends in Cognitive Sciences, 17(4), 160-165.

Gergely, G. (2013). Ostensive communication and cultural learning: The natural pedagogy hypothesis. In J. Metcalfe \& H. S. Terrace (Eds.), Agency and Joint Attention (pp. 139-151). Oxford, UK: Oxford University Press.

Gergely, G., \& Csibra, G. (2005). The social construction of the cultural mind: Imitative learning as a mechanism of human pedagogy. Interaction Studies, 6, 463-481.

Gergely, G., \& Csibra, G. (2006). Sylvia's recipe: Human culture, imitation, and pedagogy. In N. J. Enfield \& S. C. Levinson (Eds.), Roots of Human Sociality: Culture, Cognition, and Human Interaction (pp. 229-255). Berg Press: London.

Gergely, G., \& Jacob, P. (2012). Reasoning about instrumental and communicative agency in human infancy. In J. B. Benson, F. Xu, \& T. Kushnir (Eds.), Advances in child development and behavior. Vol 43: Rational constructivism in cognitive development (Vol. 43, pp. 59-94). Waltham, MA: Academic Press/Elsevier.

Germine, L., Dunn, E. C., McLaughlin, K. A., \& Smoller, J. W. (2015). Childhood adversity is associated with adult theory of mind and social affiliation, but not face processing. PLOS ONE, 10(6), e0129612.

Gibbons, R. D., Hur, K., Brown, C. H., Davis, J. M., \& Mann, J. J. (2012). Benefits from antidepressants: Synthesis of 6-week patient-level outcomes from double-blind placebo-controlled randomized trials of fluoxetine and venlafaxine. Archives of General Psychiatry, 69(6), 572-579.

Gluckman, P. D., Low, F. M., Buklijas, T., Hanson, M. A., \& Beedle, A. S. (2011). How evolutionary principles improve the understanding of human health and disease. Evolutionary Applications, 4(2), 249-263. 
Culture and Psychopathology

Gluschkoff, K., Jokela, M., \& Rosenström, T. (2019). The general psychopathology factor: Structural stability and generalizability to within-individual changes. Frontiers in Psychiatry, 10, 594.

Goldberg, D. (2015). Psychopathology and classification in psychiatry. Social Psychiatry and Psychiatric Epidemiology, 50(1), 1-5.

Goodkind, M., Eickhoff, S. B., Oathes, D. J., Jiang, Y., Chang, A., Jones-Hagata, L. B., . . Etkin, A. (2015). Identification of a common neurobiological substrate for mental illness. JAMA Psychiatry, 72(4), 305-315.

Gopnik, A., \& Wellman, H. M. (2012). Reconstructing constructivism: Causal models, Bayesian learning mechanisms, and the theory theory. Psychological Bulletin, 138(6), $1085-1108$.

Greene, A. L., Eaton, N. R., Li, K., Forbes, M. K., Krueger, R. F., Markon, K. E., . . Kotov, R. (2019). Are fit indices used to test psychopathology structure biased? A simulation study. Journal of Abnormal Psychology, 128(7), 740-764.

Groh, A. M., Fearon, R. P., van IJzendoorn, M. H., Bakermans-Kranenburg, M. J., \& Roisman, G. I. (2017). Attachment in the early life course: Meta-analytic evidence for its role in socioemotional development. . Child Development Perspectives, 11, 70-76.

Gruenfeld, D. H., Inesi, M. E., Magee, J. C., \& Galinsky, A. D. (2008). Power and the objectification of social targets. Journal of Personality and Social Psychology, 95(1), 111-127.

Hammock, E. A., \& Levitt, P. (2006). The discipline of neurobehavioral development: The emerging interface of processes that build circuits and skills. . Human Development, 49, 294- 309 .

Harden, K. P., Engelhardt, L. E., Mann, F. D., Patterson, M. W., Grotzinger, A. D., Savicki, S. L., . . Tucker-Drob, E. M. (2019). Genetic associations between executive 
Culture and Psychopathology

functions and a general factor of psychopathology. Journal of the American Academy of Child and Adolescent Psychiatry.

Harris, M. (1976). History and significance of the emic/etic distinction. . Annual review of anthropology, 5, 329-350. .

Hatoum, A. S., Rhee, S. H., Corley, R. P., Hewitt, J. K., \& Friedman, N. P. (2018). Do executive functions explain the covariance between internalizing and externalizing behaviors? Development and Psychopathology, 30(4), 1371-1387.

Higgins, J. (2020). Cognising with others in the We-Mode: a defence of 'First-Person Plural' social cognition. Review of Philosophy and Psychology.

Ho, M. C., Hsu, Y. C., Lu, M. L., Gossop, M., \& Chen, V. C. (2018). 'Cool' and 'hot' executive functions in suicide attempters with major depressive disorder. Journal of Affective Disorders, 235, 332-340.

Hrdy, S. B. (2006). Evolutionary Context of Human Development: The Cooperative Breeding Model. In C. S. Carter, L. Ahnert, K. E. Grossmann, S. B. Hrdy, M. E. Lamb, S. W. Porges, \& N. Sachser (Eds.), Attachment and Bonding: A New Synthesis (pp. 9-31). Cambridge: MIT Press.

Hrdy, S. B. (2009). Mothers and others: The evolutionary origins of mutual understanding. Cambridge, MA: The Belknap Press of Harvard University Press.

Hrdy, S. B. (2013). The 'one animal in all creation about which man knows the least'. Philosophical Transactions of the Royal Society of London, Series B: Biological Sciences, 368(1631), 20130072.

Hrdy, S. B. (2016). Development plus social selection in the emergence of "emotionally modern" humans. In C. L. Meehan \& A. N. Crittenden (Eds.), Childhood: Origins, evolution, and implications (pp. 11-44). Albuquerque, New Mexico: University of New Mexico Press. 
Culture and Psychopathology

Hyland, P., Murphy, J., Shevlin, M., Bentall, R. P., Karatzias, T., Ho, G. W. K., . . McElroy, E. (2020). On top or underneath: where does the general factor of psychopathology fit within a dimensional model of psychopathology? Psychological Medicine, 1-11.

Inesi, M. E., Botti, S., Dubois, D., Rucker, D. D., \& Galinsky, A. D. (2011). Power and choice: their dynamic interplay in quenching the thirst for personal control. Psychological Science, 22(8), 1042-1048.

Ingoldsby, E. M., Shaw, D. S., Winslow, E., Schonberg, M., Gilliom, M., \& Criss, M. M. (2006). Neighborhood Disadvantage, Parent-Child Conflict, Neighborhood Peer Relationships, and Early Antisocial Behavior Problem Trajectories. Journal of Abnormal Child Psychology, 34(3), 303-319.

Insel, T., Cuthbert, B., Garvey, M., Heinssen, R., Pine, D. S., Quinn, K., . . . Wang, P. (2010). Research domain criteria (RDoC): Toward a new classification framework for research on mental disorders. American Journal of Psychiatry, 167(7), 748-751.

Jokela, M., Batty, G. D., Vahtera, J., Elovainio, M., \& Kivimaki, M. (2013). Socioeconomic inequalities in common mental disorders and psychotherapy treatment in the UK between 1991 and 2009. British Journal of Psychiatry, 202, 115-120.

Kaczkurkin, A. N., Moore, T. M., Calkins, M. E., Ciric, R., Detre, J. A., Elliott, M. A., . . Satterthwaite, T. D. (2018). Common and dissociable regional cerebral blood flow differences associate with dimensions of psychopathology across categorical diagnoses. Molecular Psychiatry, 23(10), 1981-1989.

Karg, K., Schmelz, M., Call, J., \& Tomasello, M. (2015). The goggles experiment: Can chimpanzees use self-experience to infer what a competitor can see? Anim Behav, $105,211-221$. 
Culture and Psychopathology

Kavanaugh, S. A., Neppl, T. K., \& Melby, J. N. (2018). Economic pressure and depressive symptoms: Testing the family stress model from adolescence to adulthood. $J$ Fam Psychol, 32(7), 957-965.

Kay, C. L., \& Green, J. M. (2016). Social cognitive deficits and biases in maltreated adolescents in U.K. out-of-home care: Relation to disinhibited attachment disorder and psychopathology. Development and Psychopathology, 28(1), 73-83.

Keller, H., \& Bard, K. (Eds.). (2017). The cultural nature of attachment: Contextualizing relationships and development. Cambridge, MA: MIT Press.

Keller, H., Bard, K., Morelli, G., Chaudhary, N., Vicedo, M., Rosabal-Coto, M., . . Gottlieb, A. (2018). The myth of universal sensitive responsiveness: Comment on Mesman et al. (2017). Child Development, 89(5), 1921-1928.

Keller, H., \& Chaudhary, N. (2017). Is mother essential for attachment? Models of care in different cultures. In H. Keller \& K. A. Bard (Eds.), Contextualizing attachment: The cultural nature of attachment (pp. 109-137). Cambridge, MA: MIT Press.

Keller, H., Kartner, J., Borke, J., Yovsi, R., \& Kleis, A. (2005). Parenting styles and the development of the categorical self: A longitudinal study on mirror self-recognition in Cameroonian Nso and German families. International Journal of Behavioral Development, 29(6), 496-504.

Kessler, R. C., Chiu, W. T., Demler, O., Merikangas, K. R., \& Walters, E. E. (2005). Prevalence, severity, and comorbidity of 12-month DSM-IV disorders in the National Comorbidity Survey Replication. Archives of General Psychiatry, 62(6), 617-627.

Kirsch, I., Deacon, B. J., Huedo-Medina, T. B., Scoboria, A., Moore, T. J., \& Johnson, B. T. (2008). Initial severity and antidepressant benefits: A meta-analysis of data submitted to the food and drug administration. PLoS Medicine, 5(2), 260-268. 
Culture and Psychopathology

Kittel, R., Schmidt, R., \& Hilbert, A. (2017). Executive functions in adolescents with bingeeating disorder and obesity. International Journal of Eating Disorders, 50(8), 933941.

Knight, M. J., Air, T., \& Baune, B. T. (2018). The role of cognitive impairment in psychosocial functioning in remitted depression. Journal of Affective Disorders, 235, $129-134$.

Kofler, M. J., Sarver, D. E., Harmon, S. L., Moltisanti, A., Aduen, P. A., Soto, E. F., \& Ferretti, N. (2018). Working memory and organizational skills problems in ADHD. Journal of Child Psychology and Psychiatry, 59(1), 57-67.

Kovacs, A., Teglas, E., \& Endress, A. D. (2010). The social sense: susceptibility to others' beliefs in human infants and adults. Science, 330(6012), 1830-1834.

Kovacs, A., Teglas, E., Gergely, G., \& Csibra, G. (2017). Seeing behind the surface: communicative demonstration boosts category disambiguation in 12-month-olds. Develpomental Science, 20(6), e12485.

Laceulle, O. M., Vollebergh, W. A. M., \& Ormel, J. (2015). The structure of psychopathology in adolescence: Replication of a general psychopathology factor in the TRAILS study. Clinical Psychological Science, 3(6), 850-860.

Lahey, B. B., Applegate, B., Hakes, J. K., Zald, D. H., Hariri, A. R., \& Rathouz, P. J. (2012). Is there a general factor of prevalent psychopathology during adulthood? Journal of Abnormal Psychology, 121(4), 971-977.

Lahey, B. B., Krueger, R. F., Rathouz, P. J., Waldman, I. D., \& Zald, D. H. (2017). A hierarchical causal taxonomy of psychopathology across the life span. Psychological Bulletin, 143(2), 142-186. 
Culture and Psychopathology

Lahey, B. B., Rathouz, P. J., Keenan, K., Stepp, S. D., Loeber, R., \& Hipwell, A. E. (2015). Criterion validity of the general factor of psychopathology in a prospective study of girls. Journal of Child Psychology and Psychiatry, 56(4), 415-422.

Lahey, B. B., Van Hulle, C. A., Singh, A. L., Waldman, I. D., \& Rathouz, P. J. (2011). Higher-order genetic and environmental structure of prevalent forms of child and adolescent psychopathology. Archives of General Psychiatry, 68(2), 181-189.

Lahey, B. B., Zald, D. H., Perkins, S. F., Villalta-Gil, V., Werts, K. B., Van Hulle, C. A., . . . Waldman, I. D. (2018). Measuring the hierarchical general factor model of psychopathology in young adults. International Journal of Methods in Psychiatric Research, 27(1).

Lane, J. D., \& Harris, P. L. (2015). The roles of intuition and informants' expertise in children's epistemic trust. Child Development, 86(3), 919-926.

Lee, S. H., Ripke, S., Neale, B. M., Faraone, S. V., Purcell, S. M., Perlis, R. H., . . International Inflammatory Bowel Disease Genetics, C. (2013). Genetic relationship between five psychiatric disorders estimated from genome-wide SNPs. Nature Genetics, 45(9), 984-994.

Levy, J., Goldstein, A., \& Feldman, R. (2019). The neural development of empathy is sensitive to caregiving and early trauma. Nature Communications, 10(1905).

Lima, I. M. M., Peckham, A. D., \& Johnson, S. L. (2018). Cognitive deficits in bipolar disorders: Implications for emotion. Clinical Psychology Review, 59, 126-136.

Links, P. S., \& Eynan, R. (2013). The relationship between personality disorders and Axis I psychopathology: Deconstructing comorbidity. Annual Review of Clinical Psychology, 9, 529-554.

Liu, J., Mustanski, B., Dick, D., Bolland, J., \& Kertes, D. A. (2017). Risk and protective factors for comorbid internalizing and externalizing problems among economically 
Culture and Psychopathology

disadvantaged African American youth. Development and Psychopathology, 29(3), 1043-1056.

Lund, C., Brooke-Sumner, C., Baingana, F., Baron, E. C., Breuer, E., Chandra, P., . . Saxena, S. (2018). Social determinants of mental disorders and the Sustainable Development Goals: A systematic review of reviews. Lancet Psychiatry, 5(4), 357369.

Luyten, P., Campbell, C., Allison, E., \& Fonagy, P. (2020a). The Mentalizing Approach to Psychopathology: State of the Art and Future Directions. Annual Review of Clinical Psychology, 16, 297-325.

Luyten, P., Campbell, C., Allison, E., \& Fonagy, P. (2020b). The mentalizing approach to psychopathology: State of the art and future directions. Annual Review of Clinical Psychology.

Macdonald, A. N., Goines, K. B., Novacek, D. M., \& Walker, E. F. (2016). Prefrontal mechanisms of comorbidity from a transdiagnostic and ontogenic perspective. Development and Psychopathology, 28(4pt1), 1147-1175.

Macintosh, H. (2013). Mentalizing and its role as a mediator in the relationship between childhood experiences and adult functioning: Exploring the empirical evidence. Psihologija, 46(2), 193-212.

Markon, K. E. (2019). Bifactor and hierarchical models: Specification, inference, and interpretation. Annual Review of Clinical Psychology, 15, 51-69.

Markson, L., \& Luo, Y. (2020). Trust in early childhood. Advances in child development and behavior, 58, 137-162.

Marlowe, F. W. (2005). Who tends Hadza children? In M. E. Lamb \& B. S. Hewlett (Eds.), Hunter-gatherer childhoods: Evolutionary, developmental, and cultural perspectives (pp. 19-64). New Brunswick, NJ: Transaction Publishers. 
Culture and Psychopathology

Martel, M. M., Pan, P. M., Hoffmann, M. S., Gadelha, A., do Rosario, M. C., Mari, J. J., . . . Salum, G. A. (2017). A general psychopathology factor (P factor) in children: Structural model analysis and external validation through familial risk and child global executive function. Journal of Abnormal Psychology, 126(1), 137-148.

Masarik, A. S., \& Conger, R. D. (2017). Stress and child development: a review of the Family Stress Model. Curr Opin Psychol, 13, 85-90.

Mascaro, O., \& Sperber, D. (2009). The moral, epistemic, and mindreading components of children's vigilance towards deception. Cognition, 112(3), 367-380.

Mason, W. A., \& Capitanio, J. P. (1988). Formation and expression of filial attachment in rhesus monkeys raised with living and inanimate mother substitutes. Developmental Psychobiology, 21(5), 401-430.

McGrath, L. M., Braaten, E. B., Doty, N. D., Willoughby, B. L., Wilson, H. K., O'Donnell, E. H., . . Doyle, A. E. (2016). Extending the 'cross-disorder' relevance of executive functions to dimensional neuropsychiatric traits in youth. Journal of Child Psychology and Psychiatry, 57(4), 462-471.

McTeague, L. M., Huemer, J., Carreon, D. M., Jiang, Y., Eickhoff, S. B., \& Etkin, A. (2017). Identification of common neural circuit disruptions in cognitive control across psychiatric disorders. American Journal of Psychiatry, 174(7), 676-685.

Meehan, C. L., \& Hawks, S. (2015). Multiple attachments: Allomothering, stranger anxiety, and intimacy. In H. Otto \& H. Keller (Eds.), Different faces of attachment. Cultural variations on a universal human need (pp. 113-140). Cambridge, UK: Cambridge University Press.

Meehan, C. L., Helfrecht, C., \& Malcom, C. D. (2016). Implications of lengthy development and maternal life history: Allomaternal investment, peer relationships, and social networks. In C. L. Meehan \& A. N. Crittenden (Eds.), Childhood: Origins, evolution, 
Culture and Psychopathology

and implications (pp. 199-220). Albuquerque, New Mexico: University of New Mexico Press.

Mesman, J., Minter, T., \& Angnged, A. (2016). Received sensitivity: Adapting Ainsworth's scale to capture sensitivity in a multiple-caregiver context. Attachment and Human Development, 18(2), 101-114.

Mesman, J., Minter, T., Angnged, A., Cisse, I. A. H., Salali, G. D., \& Migliano, A. B. (2018). Universality without uniformity: A culturally inclusive approach to sensitive responsiveness in infant caregiving. Child Development, 89(3), 837-850.

Mesman, J., van IJzendoorn, M., Behrens, K., Carbonell, O. A., Carcamo, R., Cohen-Paraira, I., . . Zreik, G. (2016). Is the ideal mother a sensitive mother? Beliefs about early childhood parenting in mothers across the globe. International Journal of Behavioral Development, 40(5), 385-397.

Metcalfe, J., \& Mischel, W. (1999). A hot/cool-system analysis of delay of gratification: Dynamics of willpower. Psychological Review, 106(1), 3-19.

Moberget, T., Alnaes, D., Kaufmann, T., Doan, N. T., Cordova-Palomera, A., Norbom, L. B., ... Westlye, L. T. (2019). Cerebellar gray matter volume is associated with cognitive function and psychopathology in adolescence. Biological Psychiatry, 86(1), 65-75.

Moore, T. M., Kaczkurkin, A. N., Durham, E. L., Jeong, H. J., McDowell, M. G., Dupont, R. M., . . Lahey, B. B. (2020). Criterion validity and relationships between alternative hierarchical dimensional models of general and specific psychopathology. J Abnorm Psychol, 129(7), 677-688.

Morelli, G. A., Chaudhary, N., Gottlieb, A., Keller, H., Murray, M., Quinn, N., . . . Vicedo, M. (2017). Taking culture seriously: A pluralistic approach to attachment. . In H. Keller \& K. A. Bard (Eds.), Contextualizing attachment: The cultural nature of attachment (pp. 139-170). Cambridge, MA: MIT Press. 
Culture and Psychopathology

Murray, A. L., \& Johnson, W. (2013). The limitations of model fit in comparing the bi-factor versus higher-order models of human cognitive ability structure. Intelligence, 41(5), 407-422.

National Institute for Health and Care Excellence. (2017). Depression in adults: Recognition and management. (In development [GID-CGWAVE0725]; expected publication date: November 2017). Retrieved from London, UK:

https://www.nice.org.uk/guidance/indevelopment/gid-cgwave0725

National Institute for Health and Clinical Excellence. (2012). Conduct disorders and antisocial behaviour in children and young people: Recognition, intervention and management (Consultation version). London, UK: The British Psychological Society and the Royal College of Psychiatrists.

Neumann, A., Pappa, I., Lahey, B. B., Verhulst, F. C., Medina-Gomez, C., Jaddoe, V. W., . . . Tiemeier, H. (2016). Single nucleotide polymorphism heritability of a general psychopathology factor in children. Journal of the American Academy of Child and Adolescent Psychiatry, 55(12), 1038-1045 e1034.

NHS Digital. (2018). Mental Health of Children and Young People in England, 2017: Summary of key findings. https://files.digital.nhs.uk/F6/A5706C/MHCYP\%202017\%20Summary.pdf.

NHS England. (2014). Five Year Forward View, https://www.england.nhs.uk/wpcontent/uploads/2014/10/5yfv-web.pdf.

Niarchou, M., Moore, T. M., Tang, S. X., Calkins, M. E., McDonald-McGuinn, D. M., Zackai, E. H., . . G Gur, R. E. (2017). The dimensional structure of psychopathology in 22q11.2 deletion syndrome. Journal of Psychiatric Research, 92, 124-131. 
Culture and Psychopathology

Nigg, J. T., Jester, J. M., Stavro, G. M., Ip, K. I., Puttler, L. I., \& Zucker, R. A. (2017). Specificity of executive functioning and processing speed problems in common psychopathology. Neuropsychology, 31(4), 448-466.

O’Madagain, C., \& Tomasello, M. (2019). Joint attention to mental content and the social origin of reasoning. Synthese.

Ochs, E., \& Izquierdo, C. (2009). Responsibility in childhood: Three developmental trajectories. Ethos, 37(4), 391-413.

Olino, T. M., Bufferd, S. J., Dougherty, L. R., Dyson, M. W., Carlson, G. A., \& Klein, D. N. (2018). The development of latent dimensions of psychopathology across early childhood: Stability of dimensions and moderators of change. Journal of Abnormal Child Psychology, 46(7), 1373-1383.

Overbeck, J. R., \& Droutman, V. (2013). One for all: Social power increases self-anchoring of traits, attitudes, and emotions. Psychological Science, 24(8), 1466-1476.

Panchanathan, K., Frankenhuis, W. E., \& Barrett, H. C. (2010). Development: Evolutionary ecology's midwife. Behavioral and Brain Sciences, 33(2-3), 105-106.

Papousek, H., \& Papousek, M. (1975). Cognitive aspects of preverbal social interaction between human infants and adults. In Parent-Infant Interaction. Ciba Foundation Symposium 33 (pp. 241-260). New York, NY: Elsevier.

Patalay, P., Fonagy, P., Deighton, J., Belsky, J., Vostanis, P., \& Wolpert, M. (2015). A general psychopathology factor in early adolescence. . British Journal of Psychiatry, $206,1-8$.

Pettersson, E., Larsson, H., \& Lichtenstein, P. (2016). Common psychiatric disorders share the same genetic origin: A multivariate sibling study of the Swedish population. Molecular Psychiatry, 21(5), 717-721. 
Culture and Psychopathology

Piotrowska, P. J., Stride, C. B., Maughan, B., \& Rowe, R. (2019). Mechanisms underlying social gradients in child and adolescent antisocial behaviour. SSM - Population Health, 7, https://doi.org/10.1016/j.ssmph.2019.100353.

Podsakoff, P. M., MacKenzie, S. B., Lee, J. Y., \& Podsakoff, N. P. (2003). Common method biases in behavioral research: A critical review of the literature and recommended remedies. Journal of Applied Psychology, 88(5), 879-903.

Reeb-Sutherland, B. C., Levitt, P., \& Fox, N. A. (2012). The predictive nature of individual differences in early associative learning and emerging social behavior. PLOS ONE, 7(1), e30511.

Reise, S. P., Kim, D. S., Mansolf, M., \& Widaman, K. F. (2016). Is the bifactor model a better model or is it just better at modeling implausible responses? Application of iteratively reweighted least squares to the Rosenberg Self-Esteem Scale. Multivariate Behavioral Research, 51(6), 818-838.

Romer, A. L., Elliott, M. L., Knodt, A. R., Sison, M. L., Ireland, D., Houts, R., . . Hariri, A. R. (2020). Pervasively thinner neocortex as a transdiagnostic feature of general psychopathology. American Journal of Psychiatry.

Romer, A. L., Knodt, A. R., Houts, R., Brigidi, B. D., Moffitt, T. E., Caspi, A., \& Hariri, A. R. (2018). Structural alterations within cerebellar circuitry are associated with general liability for common mental disorders. Molecular Psychiatry, 23(4), 1084-1090.

Romer, A. L., Knodt, A. R., Sison, M. L., Ireland, D., Houts, R., Ramrakha, S., . . Hariri, A. R. (2019). Replicability of structural brain alterations associated with general psychopathology: Evidence from a population-representative birth cohort. Molecular Psychiatry. 
Culture and Psychopathology

Rosenström, T., Gjerde, L. C., Krueger, R. F., Aggen, S. H., Czajkowski, N. O., Gillespie, N. A., ... Ystrom, E. (2019). Joint factorial structure of psychopathology and personality. Psychological Medicine, 49(13), 2158-2167.

Rucker, D. D., \& Galinsky, A. D. (2017). Social power and social class: Conceptualization, consequences, and current challenges. Current Opinion in Psychology, 18, 26-30.

Rudrauf, D. (2014). Structure-function relationships behind the phenomenon of cognitive resilience in neurology: insights for neuroscience and medicine. Advances in Neuroscience, 2014( Article ID 462765).

Russell, B. B. (1940/1967). An inquiry into meaning and truth. London, UK: Allen \& Unwin.

Sallis, H., Szekely, E., Neumann, A., Jolicoeur-Martineau, A., van, I. M., Hillegers, M., . . . Evans, J. (2019). General psychopathology, internalising and externalising in children and functional outcomes in late adolescence. J Child Psychol Psychiatry, 60(11), 1183-1190.

Sandel, A. A., MacLean, E. L., \& Hare, B. (2011). Evidence from four lemur species that ringtailed lemur social cognition converges with that of haplorhine primates. Anim Behav, 81(5), 925-931.

Sato, M., Fonagy, P., \& Luyten, P. (2018). Effects of social exclusion on effortful control and mentalizing in relation to borderline personality features. Scientific Reports, 8(1), 14400.

Schaefer, J. D., Caspi, A., Belsky, D. W., Harrington, H., Houts, R., Horwood, L. J., . . Moffitt, T. E. (2017). Enduring mental health: Prevalence and prediction. Journal of Abnormal Psychology, 126(2), 212-224.

Schaefer, J. D., Moffitt, T. E., Arseneault, L., Danese, A., Fisher, H. L., Houts, R., . . Caspi, A. (2018). Adolescent victimization and early-adult psychopathology: Approaching 
Culture and Psychopathology

causal inference using a longitudinal twin study to rule out noncausal explanations. Clinical Psychological Science, 6(3), 352-371.

Schäfer, J. L., McLaughlin, K. A., Manfro, G. G., Pan, P., Rohde, L. A., Miguel, E. C., \& Salum, G. A. (2020). Cross-sectional and longitudinal associations of threat and deprivation on cognition, emotional processing and psychopathology in children and adolescents. bioRxiv.

Sedgwick, O., Young, S., Baumeister, D., Greer, B., Das, M., \& Kumari, V. (2017). Neuropsychology and emotion processing in violent individuals with antisocial personality disorder or schizophrenia: The same or different? A systematic review and meta-analysis. Australian and New Zealand Journal of Psychiatry, 51(12), 11781197.

Sellbom, M., \& Tellegen, A. (2019). Factor analysis in psychological assessment research: Common pitfalls and recommendations. Psychological Assessment, 31(12), 14281441.

Sellers, R., Wells, A., \& Morrison, A. P. (2018). Are experiences of psychosis associated with unhelpful metacognitive coping strategies? A systematic review of the evidence. Clinical Psychology \& Psychotherapy, 25(1), 31-49.

Selzam, S., Coleman, J., Caspi, A., Moffitt, T., \& Plomin, R. (2018). A polygenic p factor for major psychiatric disorders. Translational Psychiatry, 8(1), 205.

Shafto, P., Eaves, B., Navarro, D. J., \& Perfors, A. (2012). Epistemic trust: Modeling children's reasoning about others' knowledge and intent. Developmental Science, $15(3), 436-447$.

Shanmugan, S., Wolf, D. H., Calkins, M. E., Moore, T. M., Ruparel, K., Hopson, R. D., . . . Satterthwaite, T. D. (2016). Common and dissociable mechanisms of executive 
Culture and Psychopathology

system dysfunction across psychiatric disorders in youth. American Journal of Psychiatry, 173(5), 517-526.

Shields, A. N., Reardon, K. W., Brandes, C. M., \& Tackett, J. L. (2019). The p factor in children: Relationships with executive functions and effortful control. Journal of Research in Personality, 82.

Simpson, J. A., Collins, W. A., Tran, S., \& Haydon, K. C. (2007). Attachment and the experience and expression of emotions in romantic relationships: A developmental perspective. Journal of Personality and Social Psychology, 92(2), 355-367.

Smith, G. T., Atkinson, E. A., Davis, H. A., Riley, E. N., \& Oltmanns, J. R. (2020). The General Factor of Psychopathology. Annual Review of Clinical Psychology.

Smoller, J. W. (2013). Disorders and borders: Psychiatric genetics and nosology. American Journal of Medical Genetics. Part B, Neuropsychiatric Genetics, 162B(7), 559-578.

Snyder, H. R., Friedman, N. P., \& Hankin, B. L. (2019). Transdiagnostic mechanisms of psychopathology in youth: Executive functions, dependent stress, and rumination. Cognitive Therapy and Research, 43(5), 834-851.

Snyder, H. R., Hankin, B. L., Sandman, C. A., Head, K., \& Davis, E. P. (2017). Distinct patterns of reduced prefrontal and limbic gray matter volume in childhood general and internalizing psychopathology. Clinical Psychological Science.

Snyder, H. R., Miyake, A., \& Hankin, B. L. (2015). Advancing understanding of executive function impairments and psychopathology: Bridging the gap between clinical and cognitive approaches. Frontiers in Psychology, 6, 328.

Snyder, H. R., Young, J. F., \& Hankin, B. L. (2017a). Chronic stress exposure and generation are related to the p-factor and externalizing specific psychopathology in youth. Journal of Clinical Child and Adolescent Psychology, 1-10. 
Culture and Psychopathology

Snyder, H. R., Young, J. F., \& Hankin, B. L. (2017b). Strong homotypic continuity in common psychopathology-, internalizing-, and externalizing-specific factors over time in adolescents. Clinical Psychological Science, 5(1), 98-110.

Song, J., Bergen, S. E., Kuja-Halkola, R., Larsson, H., Landen, M., \& Lichtenstein, P. (2015). Bipolar disorder and its relation to major psychiatric disorders: A family-based study in the Swedish population. Bipolar Disorders, 17(2), 184-193.

Sperber, D. (1990). The epidemiology of beliefs. In C. Fraser \& G. Gaskell (Eds.), The social psychological study of widespread beliefs (pp. 25-44). Oxford: Clarendon Press.

Sperber, D., Clement, F., Heintz, C., Mascaro, O., Mercier, H., Origgi, G., \& Wilson, D. (2010). Epistemic vigilance. Mind and Language, 25(4), 359-393.

Sperber, D., \& Wilson, D. (1995). Relevance: Communication and cognition (2nd ed.). Malden, MA: Blackwell.

Stievenart, M., Roskam, I., Meunier, J. C., \& Van de Moortele, G. (2011). The reciprocal relation between children's attachment representations and their cognitive ability. . International Journal of Behavioral Development, 35, 58-66.

Strack, F., \& Deutsch, R. (2004). Reflective and impulsive determinants of social behavior. Personality and Social Psychology Review, 8(3), 220-247.

Szasz, T. (1960). The myth of mental illness. American Psychologist, 15(2), 113-118.

Taubner, S., \& Curth, C. (2013). Mentalization mediates the relation between early traumatic experiences and aggressive behavior in adolescence. Psihologija, 46(2), 177-192.

Tomasello, M. (2016). A natural history of human morality. Cambridge, MA: Harvard University Press.

Tomasello, M. (2018). How children come to understand false beliefs: A shared intentionality account. Proceedings of the National Academy of Sciences of the United States of America, 115(34), 8491-8498. 
Culture and Psychopathology

Tomasello, M. (2019). Becoming human: A theory of ontogeny. Cambridge, MA: The Belknap Press of Harvard University Press.

Tomasello, M. (2020). The role of roles in uniquely human cognition and sociality. Journal for the theory of social behaviour, 50(1).

Tomasello, M., Call, J., \& Kaminski, J. (2006). Goats' behaviour in a competitive food paradigm: Evidence for perspective taking? Behaviour, 143(11), 1341-1356.

Tomasello, M., Carpenter, M., Call, J., Behne, T., \& Moll, H. (2005). Understanding and sharing intentions: The origins of cultural cognition. Behavioral and Brain Sciences, 28(5), 675-691.

Tong, Y., Wang, F., \& Danovitch, J. (2020). The role of epistemic and social characteristics in children's selective trust: Three meta-analyses. Developmental Science, 23(2), e12895.

Tronick, E. Z. (2008). Emotional connections and dyadic consciousness in infant-mother and patient-therapist interactions: Commentary on paper by frank m. Lachmann. Psychoanalytic Dialogues, 11(2), 187-194.

Tuomela, R. (2005). We-intentions revisited. Philosophical Studies, 125(3), 327-369.

Twemlow, S. W., Fonagy, P., \& Sacco, F. C. (2013). A developmental approach to mentalizing communities through the Peaceful Schools experiment. In N. Midgley \& I. Vrouva (Eds.), Minding the child: Mentalization-based interventions with children, young people and their families (pp. 187-201). Hove, UK: Routledge.

Unterrainer, J. M., Domschke, K., Rahm, B., Wiltink, J., Schulz, A., Pfeiffer, N., . . Beutel, M. (2018). Subclinical levels of anxiety but not depression are associated with planning performance in a large population-based sample. Psychological Medicine, $48(1), 168-174$. 
Culture and Psychopathology

van Bork, R., Epskamp, S., Rhemtulla, M., Borsboom, D., \& van der Maas, H. L. J. (2017). What is the $p$-factor of psychopathology? Some risks of general factor modeling. Theory \& Psychology, 27(6), 759-773.

van Harmelen, A. L., Kievit, R. A., Ioannidis, K., Neufeld, S., Jones, P. B., Bullmore, E., .. . Goodyer, I. (2017). Adolescent friendships predict later resilient functioning across psychosocial domains in a healthy community cohort. Psychological Medicine, 1-11. van IJzendoorn, M. H., Dijkstra, J., \& Bus, A. G. (1995). Attachment, intelligence, and language: A meta-analysis. Social Development, 4, 115-128.

Vine, V., Byrd, A. L., Mohr, H., Scott, L. N., Beeney, J. E., \& Stepp, S. D. (2020). The structure of psychopathology in a sample of clinically referred, emotionally dysregulated early adolescents. Journal of Abnormal Child Psychology.

Wade, M., Fox, N. A., Zeanah, C. H., \& Nelson, C. A. (2018). Effect of foster care intervention on trajectories of general and specific psychopathology among children with histories of institutional rearing: A randomized clinical trial. JAMA Psychiatry, 75(11), 1137-1145.

Wade, M., Fox, N. A., Zeanah, C. H., \& Nelson, C. A., 3rd. (2019). Long-term effects of institutional rearing, foster care, and brain activity on memory and executive functioning. Proceedings of the National Academy of Sciences of the United States of America, 116(5), 1808-1813.

Waldman, I. D., Poore, H. E., Luningham, J. M., \& Yang, J. (2020). Testing structural models of psychopathology at the genomic level. World Psychiatry, 19(3), 350-359.

Waldman, I. D., Poore, H. E., van Hulle, C., Rathouz, P. J., \& Lahey, B. B. (2016). External validity of a hierarchical dimensional model of child and adolescent psychopathology: Tests using confirmatory factor analyses and multivariate behavior genetic analyses. Journal of Abnormal Psychology, 125(8), 1053-1066. 
Culture and Psychopathology

Watts, A. L., Poore, H. E., \& Waldman, I. D. (2019). Riskier tests of the validity of the bifactor model of psychopathology. Clinical Psychological Science, 7(6), 1285-1303.

White, L. K., Moore, T. M., Calkins, M. E., Wolf, D. H., Satterthwaite, T. D., Leibenluft, E., ... Gur, R. E. (2017). An evaluation of the specificity of executive function impairment in developmental psychopathology. Journal of the American Academy of Child and Adolescent Psychiatry, 56(11), 975-982 e973.

Wilkinson, R., \& Pickett, K. (2009). The spirit level: Why equality is better for everyone. London, UK: Penguin Books.

Winnicott, D. W. (1956). Mirror role of mother and family in child development. In D. W. Winnicott (Ed.), Playing and reality (pp. 111-118). London, UK: Tavistock.

Wise, T., Radua, J., Via, E., Cardoner, N., Abe, O., Adams, T. M., . . Arnone, D. (2016). Common and distinct patterns of grey-matter volume alteration in major depression and bipolar disorder: Evidence from voxel-based meta-analysis. Molecular Psychiatry.

Wolf, E. J., Miller, M. W., Krueger, R. F., Lyons, M. J., Tsuang, M. T., \& Koenen, K. C. (2010). Posttraumatic stress disorder and the genetic structure of comorbidity. Journal of Abnormal Psychology, 119(2), 320-330.

Yang, M., Coid, J., \& Tyrer, P. (2010). Personality pathology recorded by severity: National survey. British Journal of Psychiatry, 197(3), 193-199.

Zanarini, M. C., Yong, L., Frankenburg, F. R., Hennen, J., Reich, D. B., Marino, M. F., \& Vujanovic, A. A. (2002). Severity of reported childhood sexual abuse and its relationship to severity of borderline psychopathology and psychosocial impairment among borderline inpatients. Journal of Nervous and Mental Disease, 190(6), 381387. 
Culture and Psychopathology

Zimmerman, M., Martinez, J. H., Friedman, M., Boerescu, D. A., Attiullah, N., \& Toba, C. (2012). How can we use depression severity to guide treatment selection when measures of depression categorize patients differently? Journal of Clinical Psychiatry, 73(10), 1287-1291.

Zimmerman, M., Martinez, J. H., Young, D., Chelminski, I., \& Dalrymple, K. (2013).

Severity classification on the Hamilton Depression Rating Scale. Journal of Affective Disorders, 150(2), 384-388.

Zimmerman, M., Morgan, T. A., \& Stanton, K. (2018). The severity of psychiatric disorders. World Psychiatry, 17(3), 258-275. 